\title{
Lexis
}

Journal in English Lexicology

16 | 2020

Diachronic Lexical Semantics

\section{Am I Way Wrong on this One? On the Multiple Semantic Sources and Paths of Development of the Amplifier Way in American English}

\section{Hélène Margerie}

\section{OpenEdition}

Journals

Electronic version

URL: http://journals.openedition.org/lexis/4733

DOI: $10.4000 /$ lexis.4733

ISSN: 1951-6215

Publisher

Université Jean Moulin - Lyon 3

\section{Electronic reference}

Hélène Margerie, "Am I Way Wrong on this One? On the Multiple Semantic Sources and Paths of Development of the Amplifier Way in American English", Lexis [Online], 16 | 2020, Online since 17 December 2020, connection on 21 January 2021. URL: http://journals.openedition.org/lexis/4733 ; DOI: https://doi.org/10.4000/lexis.4733

This text was automatically generated on 21 January 2021.

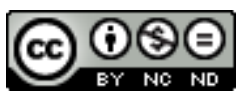

Lexis is licensed under a Creative Commons Attribution-NonCommercial-NoDerivatives 4.0 International License. 


\title{
Am I Way Wrong on this One? On the Multiple Semantic Sources and Paths of Development of the Amplifier Way in American English
}

\author{
Hélène Margerie
}

\section{Introduction}

1 This article ${ }^{1}$ explores the diachronic semantic development of the intensifier ${ }^{2}$ way in American English illustrated in (1)-(2):

(1) She didn't care if he was old enough to be her grandfather - or greatgrandfather by now; and Margalo did agree that he was incredibly handsome. But there was old, and there was way old, and Gregory Peck was definitely in the second category. [COHA, Bad Girls in Love, 2002]

(2) "These guys really bugged you, didn't they?" "No", I replied with a sigh. "They just have different interests. Way different." [COHA, The Chicken Asylum, 2001]

2 Way belongs to the category of amplifiers which scale upwards (Quirk et al. [1985: 590]). Quirk et al. [1985:590] divide amplifiers into maximizers, which refer to the upper extreme of the scale, and boosters, which denote a high point on a scale. According to the Oxford English Dictionary (OED s.v. way adv.3), way in its intensifying use means 'extremely, very'; it thus functions as a booster. In (3), way cool can indeed be paraphrased as 'so cool', ${ }^{3}$ but the collocation with wrong in (4) may rather suggest that way functions as a maximizer, being (more or less) synonymous with absolutely or completely: 
(3) Lisabette (Clapping her hands.) "She's going to be in the play. This is way cool!" (To Casey) "Isn't that cool?" Casey (Smiling, but a bit reserved): “Yes, cool." [COHA, Playscript of Anton in Show Business, 1999]

(4) "You got how much money of your own?" Matt stood up, hat in hand, and said mournfully, "Only three hundred and eighteen dollars, so I guess I've got a lot of gall to take up your time. You wouldn't be interested in my little stake." "Sit down, man, sit down," boomed the contractor and waved his seegar in an expansive gesture. "You're wrong, way wrong" [COHA, Love is Eternal, 1954]

It typically modifies an adjective in the absolute (see (1)-(4)) or the comparative degree, as in (5), or an adjectival head already pre-modified by (amplifier) too (OED s.v. way adv. $3)$, as in (6):

(5) In his eyes there's this look. Like he was seeing something different, something important, something way bigger than Fairhope. [COHA, Doing Alien, 1994]

(6) "Don't go out in this, Beck," Lucy said. "Hit's way too bad a night." [COHA, The Voice at the Back Door, 1956]

4 Way is thus quite specific within the class of amplifiers. It differs from very, the prototypical booster, which cannot modify an adjective in the comparative degree or precede the sequence <too ADJ[ECTIVE]> ( ${ }^{*}$ very cooler; *very too cool) (Quirk et al. [1985: 473]). Way is also distinct from amplifier much which does collocate with adjectives in the comparative degree (much longer; much more convenient) or adjectives pre-modified by too (much too expensive), but not adjectives in the absolute degree (e.g. * I must have read the directions much wrong). Way can also modifiy an adverb, a verb, or a noun, as in (7), (8) and (9), respectively:

(7) "You move reality generator too far," he said amiably. "Mess up everything way bad." [COHA, The Attack of the Ignoroids, 1999]

(8) "You don't think I'll do it," she had told him as she raced through another set of sit-ups. "You way underestimate me." [COHA, Assassins, 2000]

(9) When we recorded it originally I doubled up the drums and it sounded way Gary Glitter, way Clash. [OED s.v. way adv.3, 199021 July 14/6]

Intensification in the English language is a very popular topic of research. Earlier studies have focused, among other issues, on synchronic structural, semantic and sociolinguistic properties of various individual intensifiers in several present-day varieties of English (e.g. Stoffel [1901]; Bolinger [1972]; Bäcklund [1973]; Altenberg [1991]; Paradis [1997], [2000], [2001]; Stenström [2000]; Ito \& Tagliamonte [2003]; Tagliamonte \& Roberts [2005]; Macauley [2006]; Xia \& Tao [2007]; Tagliamonte [2008]), or explored the origins of their intensifying function, often accounted for in terms of grammaticalization (e.g. Peters [1992]; Adamson [2000]; Lorenz [2002]; Nevalainen \& Rissanen [2002]; Méndez-Naya [2003], [2012]; Buchstaller \& Traugott [2006]; Traugott [2008a], [2008b]; Breban \& Davidse [2016]). It has been shown that degree adverbs, especially boosters, develop from items or constructions performing various types of modification, such as manner adverbs (e.g. fairly, pretty), spatial adverbs (e.g. right, downright), quantitative adverbs (e.g. much), qualitative adverbs (e.g. terribly), emphasizers (really), taboo/swear words (e.g. bloody) (see e.g. Fettig [1934]; Peters 
[1994]; Nevalainen \& Rissanen [2002]; Napoli \& Hoeksema [2009]; Mendéz-Naya [2006], [2008], [2014]).

6 Interestingly, the amplifier way is said to be descendent of away (Kirchner [1955]; Bolinger [1972]; Méndez-Naya [2012: 369]; King [2016]; see also OED s.v. away adv. 9b) which belongs to the category of spatial adverbs. However, there has been - to the best of my knowledge - no diachronic corpus-based study conducted to investigate its origins. In an attempt to lay the groundwork of a general theory that can explain why a given source word grammaticalizes as one type of intensifier rather than another, King [2016] focuses on three intensifiers, including way, which were not chosen randomly but "specifically because they are transparently related to source words that have spatial meanings" (King [2016:3]). King [2016:3] provides the following examples as evidence of the origin of way as a reduced form of spatial away:

(10) Mitchell, that letter DeWitt wrote you, has gone away - way down yonder.

(11) Such a lovely blue sky away, way up so high!

7 While I consider that the spatial reading illustrated in (10)-(11) may indeed come into play in the semantic development of amplifier way, I propose that the spatial meaning of away is not the only semantic source involved. This contrasts with most case studies on language change which "generally focus on just one construction, drawing straight lines between a construction and a single historical ancestor" (Van de Velde et al. [2015: 1]). In line with a more recent view that more than one source construction may be involved in language change, whether the latter be traced back to independent constructions with their own history or to different uses of the same construction (Van de Velde et al. [2015: 1-2]; see also Breban \& De Smet [2019: 879]), I suggest that multiple sources are at the origin of the development of the degree meaning of way. My assumption is based on an extensive corpus-based analysis of the functional uses of several constructions involving (a)way in American English that may have shaped over time the development of the degree meaning illustrated in (1)-(6) above. In the present article, I will focus on patterns involving both way in various uses and an adjectival head, e.g. <way $\mathrm{ADJ}>$, < (in) every way $\mathrm{ADJ}>$, <a long/good/great way $\mathrm{ADJ}>.^{4}$ The data extracted from the Corpus of Historical American English suggest that (i) the role of the spatial meaning in the semantic development of amplifier way may not only be related to the spatial adverb away but also to other spatial constructions such as $<a$ long/good/ great way(s) PREP[OSITION]/ADV[ERB $]_{\text {spatial }}>$ and $<a$ way(s) PREP/ADV spatial $>$, and that (ii) other source constructions need to be taken into account, i.e. the originally manner constructions $<\mathrm{ADJ}$ (in) every ways and < (in) every way $\mathrm{ADJ}>$. It will thus be assumed that way followed various developmental paths which may have interlocked at some point.

8 This will lead me to address the related issue of the mechanism(s) and causes of change involved in the semantic-pragmatic development of the amplifier way. I will propose that the rise of the degree meaning may result from the interplay between several mechanisms or causes of change, i.e. metaphorization, pragmatic inferencing, and also analogization, i.e. the mechanism related to analogical thinking (see e.g. Traugott [2011:25]), based on speakers' recognition of similarities with other extant degree modifier constructions, most prominently the degree modifier construction <far ADJ> (far better, far different). 
The framework of constructionalization (Traugott \& Trousdale [2013]) will provide the main background for the discussion. Constructionalization is a basic concept in a Diachronic Construction Grammar approach to language change (Noël [2007]) which came about in the spirit of rethinking grammaticalization in constructional terms. While grammaticalization refers to "that part of the study of language change that is concerned with such questions as how lexical items and constructions come in certain linguistic contexts to serve grammatical functions or how grammatical items develop new grammatical functions" (Hopper \& Traugott [2003: 1]), constructionalization is defined as the rise of form-meaning pairings, in other words 'constructions' (see e.g. Goldberg [1995], [2006]; Fillmore \& Kay [1997]; Croft [2001]), out of previously nonaligned material (Traugott \& Trousdale [2013:22]). Constructionalization follows multiple small constructional changes of both form and meaning, the outcome of which is the creation of a form new -meaning $_{\text {new }}$ pairing (see e.g. Traugott [2015:51]). Grammatical constructionalization encompasses much of what has been discussed in the grammaticalization literature, but it goes beyond it to consider more far-reaching morphosyntactic changes. Indeed, another key concept in Diachronic Construction Grammar is the concept of taxonomic hierarchy. Constructions operate in a network which involves inheritance from the more abstract to the less schematic constructions. Traugott [2008a: 30], [2008b: 236] has distinguished the following constructional levels, with different degrees of schematicity:

(i) macro-constructions: highly abstract, schematic constructions

(ii) meso-constructions: sets of similarly behaving constructions

(iii) micro-constructions: individual construction types

(iv) constructs: empirically attested tokens of micro-constructions

In later work, Traugott \& Trousdale [2013] use the terms schema and subschema instead of macro- and meso-construction, ${ }^{5}$ and Traugott [2019] makes a distinction between a micro-construction, a micro-schema and a more abstract schema:

\begin{abstract}
A "micro-construction" is a low-level substantive-type construction such as after all in its discourse-marker use, a micro-schema is a low-level substantive-type construction that has a substantive part and one or more open slots, e.g. all but $X$, what is $X$ doing $Y$ ? Higher-level schemas consist of abstract slots (e.g. ditransitive SUBJ V OBJ1 OBJ2 such as I gave her a book); how many higher-levels schemas are posited depends on the level of systemic generalization that the researcher is interested in (e.g. ditransitives are a subset of transitives) (Traugott [2019: 127]).
\end{abstract}

In this paper I will adopt a constructionalist perspective on language change which supports the idea that pattern matching is an important factor of change, because construction grammar highlights memberships of sets (for constructional analyses of other degree modifier constructions, see e.g. Traugott [2019:132-138]; Trousdale [2012: 178-186]). I will discuss analogization and paradigmatization, i.e. alignment with other constructions in an extant schema (Traugott [2019]; Traugott \& Trousdale [2010: 38]), as potential key factors of change in the development of the micro-schema $<w a y_{\text {amp[lifier] }}$ ADJ>, possibly acting in concert with metaphorization and inferencing. Considering the topic of the present issue, the main focus in this paper will be on the diachronic semantic changes leading to the emergence of the amplifier wayconstruction. ${ }^{6}$ It will still occasionally address the question of morphosyntactic change(s) in order to support an analysis in terms of constructionalization.

The organization of the paper is as follows. Section 1 provides information about the data and methodology. In Section 2 I examine corpus data concerning various micro- 
schemas involving way which may be at the origin of the degree meaning of the amplifier, and other micro-schemas in the network of degree modifiers in English that may have shaped this meaning. Section 3 provides a summary of the findings and some conclusions which enable us to couch the development of the amplifier wayconstruction in terms of grammatical constructionalization.

\section{Data and methodology}

The investigation of the historical development of amplifier way in Section 2 will rely on a dataset collected from the Corpus of Historical American English (COHA) which contains 385 million words of American English from 1810-2009, grouped by decades. In addition to the "bad-data problem" (Labov [1966: 100])7 which is a well-known issue in historical linguistics, there arises the issue of the type of material contained in the corpus. COHA covers only written genres, i.e. fiction, magazines, newspapers and nonfiction books. It is thus restricted in the type of material it contains that may be relevant for the present study of an amplifier which is more characteristic of spoken than written (American) English. Since conversations as such or other forms of spoken language are not included, it could be considered difficult to reconstruct the diachronic semantic path(s) of change leading to the present-day uses of the amplifier way on the basis of written data only. ${ }^{8}$ However, the written data in COHA include represented conversation in fiction. Although they differ from the speech language users produce in spontaneous conversation, they give us "considerable insight into interactional language use" (Traugott [2019: 132]; see also Jucker et al. [1999]; Culpeper \& Kytö [2010]), ${ }^{9}$ thus giving credit to the present attempt to formulate hypotheses as to the origins and semantic development of amplifier way on the basis of data extracted from COHA. The data collected were not restricted to a particular genre so as to cover as fully as possible the history of the different micro-constructions or schemas that may have played a part in the semantic development of the micro-schema <way ${ }_{\text {amp }}$ ADJ>. Note that the genre and subgenre balance in COHA stays almost identical from decade to decade.

14 As mentioned earlier, the investigation of the amplifier uses of way in PDE was restricted to constructions in which way collocates with adjectival heads, whether in the absolute or the comparative forms, or premodified by too (see Section 2.1.). For historical data, I first relied on the OED's entries for way, and selected all the sequences which could have had a semantic bearing on the historical development of the microschema $<w a y_{\text {amp }}$ ADJ>. What were considered to be relevant patterns were:

(i) sequences in which an adverbial phrase including way modifies an adjective and expresses high degree, i.e. <(by) a long way ADJ>, <a good/great way ADJ> and <all the way ADJ> (OED s.v. way n.12d), as in (12):

(12) I'm sure it is a long way better to keep yourself to yourself. [COHA, The Squire of Sandal Side, 1886]

(ii) sequences in which adverbial way modifies a spatial preposition or adverb (OED s.v. way adv.2a and 2b; s.v. away adv. 9b), i.e. < way ${ }_{\text {adv }}$ PREP/ADV spatial 'at or by a considerable distance, far'. An example is provided in (13): 
(13) I'b been hunting you, eber since yesterday mornin', way up to de Skippack creek, sixteen miles from here, as true as my name am Charles de Fust. [COHA, Herbert Tracy, or, The Legend of the Black Rangers, 1844]

The pattern $<w_{a y} a_{\text {adv }}$ PREP/ADV spatial $>$ was thought to be worth investigating because in both this pattern and the amplifier micro-schema, way has a premodifying function and expresses high degree or some idea related to it ('a considerable distance'). Furthermore, as mentioned in the Introduction, it is sometimes reported in the literature that the amplifier way is descendent of spatial adverbial (a)way (Kirchner [1955]; Bolinger [1972]; Méndez-Naya [2012: 369]; King [2016]; see also OED s.v. away adv. 9b). The lack so far of corpus-based analyses meant to trace down its historical development from the spatial construction $<w a y_{\text {adv }}$ PREP/ADV spatial $>$ led me to put this hypothesis to the test. The data in COHA showed 17 different (originally spatial) prepositions or adverbs collocating with the adverbial modifier way in this specific pattern, namely up, out, down, over, before, back, past, under, off, beyond, after, ahead, behind, above, beneath, below and away.

(iii) sequences in which an adverbial phrase including way modifies a spatial preposition or adverb, i.e. <a long/good/great way(s) PREP/ADV $V_{\text {spatial }}>$ 'at or by a considerable distance, far' (OED s.v. way n.12b), and <a way(s) PREP/ADV spatial $>$ in which $a$ way(s) is a reduced version of <a long/good/great/little way(s), according to the OED (s.v. way n.12b; s.v. way n. and int.P3). These are illustrated in (14) and (15):

\begin{abstract}
(14) [T]he Israelites during the thirty-seven years of their journeying from Mount Sinai may have gone by those tracts of country in which the waters from Horeb could follow them, till in the thirty-ninth year of the Exodus they came to Ezion-gaber (Num. xxxiii. 36), which was a part of the Red Sea a great way down the Arabian side. [COHA, Autobiography of Frank G. Allen, Minister of the Gospel and Selections from his Writings, 1887]

(15) "Mr. Barnes -- he is with you?" It was Constance that spoke. "Yes; but --" "Where is he?" "We left him a ways down the road and --". The sound of a horse's hoof beats in front of the manor, breaking in on this explanation, was followed by hurried footsteps upon the porch. [COHA, The Strollers, 1902]
\end{abstract}

There are reasons to believe that if the construction $<w_{a y}$ adv $_{\text {PREP }} / \mathrm{ADV}_{\text {spatial }}>$ could possibly have favoured the semantic development of $<w a y_{\text {amp }} \mathrm{ADJ}>$, as suggesteg by King [2016] (see also Section 2.2.1.), then the other spatial patterns <a long/good/great way(s) $\mathrm{PREP} / \mathrm{ADV}_{\text {spatial }}>$ and $<a$ way(s) PREP/ADV $\mathrm{Apatial}_{\text {s }}>$ could have had a similar influence. Note for that matter that the above-mentioned constructions of degree or extent $<$ (by) a long way $\mathrm{ADJ}>,<a$ good/great way $\mathrm{ADJ}>$ and <all the way $\mathrm{ADJ}>$ are thought to be figurative uses of $<$ long/good/great way PREP/ADV spatial $>$ (OED s.v. way n.12d). The same prepositions or adverbs which were found as collocates of adverbial way in the pattern $<w_{\text {adv }}$ PREP/ $\mathrm{ADV}_{\text {spatial }}>$ were searched for as potential collocates of a long/good/great way(s) and a way(s) in the patterns <a long/good/great way(s) $\mathrm{PREP} / \mathrm{ADV}_{\text {spatial }}>$ and $<a$ way(s) PREP/ $\mathrm{ADV}_{\text {spatial }}>$.

For purposes of historical reconstruction, the following constructions were also examined:

(i) the patterns < (in) every way ADJ> and <ADJ (in) every way> which were encountered when investigating some of the above-mentioned constructions. Manual pruning was required to eliminate false positives (e.g. privileged in every way imaginable in which the 
phrase in every way does not modify the adjective imaginable). From a semanticpragmatic viewpoint, the data show that both < (in) every way ADJ> and <ADJ (in) every way > 'ADJ in every respect' can give rise to a meaning of high degree (see Section 2.2.3.), hence their relevance for the present study..$^{10}$ One example is provided in (16):

(16) In George Manning the physical and intellectual man had been developed in rare harmony. He was taller and larger every way than his brother Henry [...]. [COHA, Evenings at Donaldson Manor Or, The Christmas Guest, 1871]

21 (ii) a construction which shows functional and semantic similarities with the pattern $<w_{a y} y_{\text {amp }}$ ADJ>, i.e. $<f a r_{\text {amp }}$ ADJ> illustrated in (17):

(17) That's an old trick. The scheme I've been thinking of is far easier, and I'll confide it to you. [COHA, Accusation, 1817]

This pattern is attested earlier than the amplifier way-construction, and it is thus considered to be a quite plausible analogical model.

Though COHA is a large-scale resource for studying language change in English, it is not without its limitations. One of the shortcomings which complicated the task and increased the time required to complete it is part of speech tagging which sometimes turned out to be inaccurate. Davies [2012], the creator of COHA, acknowledges the problem and remarks that "tagging for nearly 100,000 'problematic' types from the 1800 s has been manually reviewed and corrected." Still, some of the searches conducted for the present paper show that further efforts need to be made in that direction. For instance, part of speech tagging turned out to be an issue when searching for adverbial way in collocation with spatial prepositions or adverbs (see Section 2.2.). A wide search for way tagged as an adverb in collocations with a preposition returned fewer results for each of the possible prepositional collocates (e.g. down, up; see above) than a more specific search for adverbial way collocating with each of the individual prepositions isolated. But even the latter sometimes yielded fewer results than those obtained when conducting the same search without tagging way as an adverb. I therefore decided to keep tagging to a minimum in this particular case, which required extensive manual pruning of the whole dataset to eliminate numerous irrelevant data (e.g. nominal uses of way followed by a spatial particle as in on the way down).

I relied upon the original division of the corpus into individual decades to examine step-by-step developments from 1810 to 2009 of each of the contructions that were likely to be relevant to the present study, namely $<w_{a y}{ }_{\text {amp }} A D J>-$ whether the adjective be in the absolute, in the inflectional or periphrastic (more/less) comparative form, or premodified by too (see Section 2.1.) - <a long/good/great way ADJ>, <all the way ADJ>, $<$ way $_{\text {adv }}$ PREP/ADV spatial $>, \quad<a$ long/good/great way(s) PREP/ADV spatial $>, \quad<f a r_{\text {amp }}$ $\mathrm{ADJ}_{\mathrm{c}[0] \mathrm{mp}[\mathrm{arative}]}>$ and $<f a r_{\text {amp }}$ too $\mathrm{ADJ}>$. Table 1 provides the raw figures and, underneath, the relative frequencies of the intensifying construction(s) under study and the patterns that might have shaped its development. 
Table 1. Raw figures and relative frequencies of the amplifier micro-schema <way ADJ> and the constructions that may be involved in its semantic development

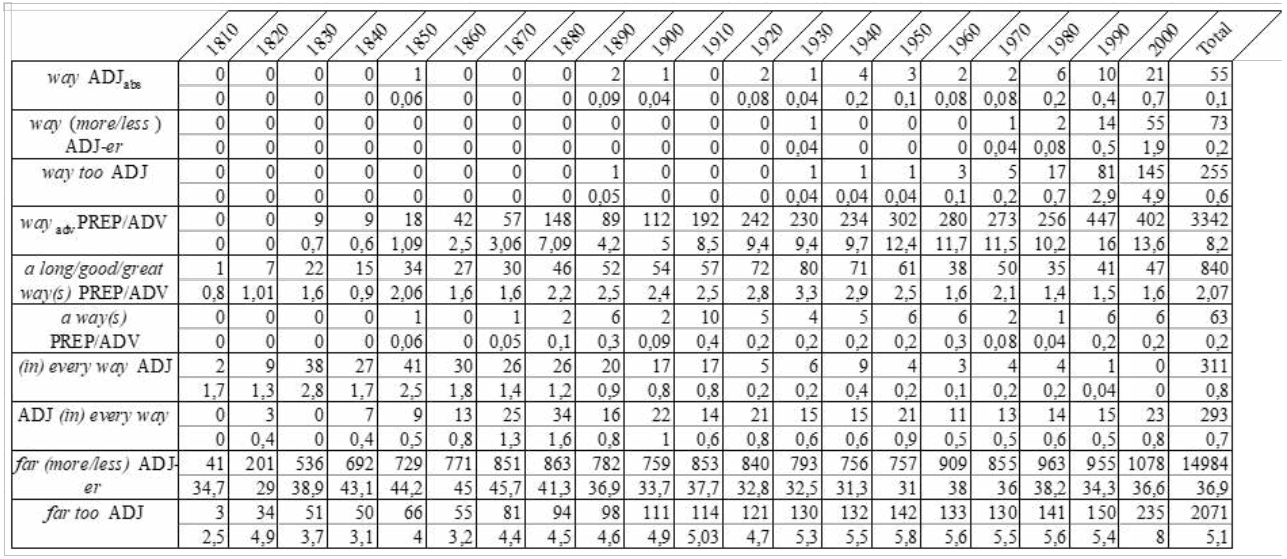

The patterns < $<$ long/good/great way ADJ> or <all the way ADJ> were finally not included in Table 1 because the search in COHA of the phrases a long/good/great way and all the way as modifiers of any adjectival collocates yielded very few, if any, results - eight tokens of the pattern <a long way> and three of <all the way ADJ>, which are illustrated in (18) and (19), but none of <a good/great way ADJ>.

(18) The old-fashioned motive-power of the rod and ferule has made many a good scholar and true lover of learning, although the ideal educator is one who, without swerving from his disciplinary course, yet contrives to make it all the way alluring. [COHA, North American Review, 1871]

(19) If you plan for to-morrow, plan a bit of pleasure with it; that's a long way better than expecting a headache. [COHA, St. Pierre's Studies of Nature, 1836]

The paucity of data concerning these constructions led me to discard them as potential sources of development of the construction <way $y_{\text {amp }}$ ADJ> (examined in Section 2), at least on the basis of the data retrieved from COHA. Still, it could be rather surprising considering the existence of another pattern of extent based on the nominal use of way, i.e. <half-way ADJ> (OED s.v. half-way A.adv). The latter was hit upon when searching for $<$ way $_{\text {amp }} \mathrm{ADJ}>$. Though it expresses moderate, not high degree, as shown in (20), it could support the idea that nominal uses of way in phrases of extent did have the semantic potential to give rise to the amplifer use of way.

(20) I don't know where he is most of the time now and I lie awake telling myself what a fool I am to care -- but when I hear his key in the latch everything in the world is all right again. I go to sleep half way happy -trying to make myself think this one will pass too. [COHA, When Ladies meet, 1932]

Tokens of <half-way ADJ> in COHA are, however, limited to about 40. A possible conclusion is that there may have been signs of a budding development of a degree meaning out of such constructions of extent based on the nominal use of way, but the low frequency and productivity of these patterns may have prevented them from developing further. 


\section{Development of the degree meaning}

with adjectival heads, and then address the issue of the semantic paths of development it may have embarked on.

\subsection{Amplifier}

The amplifier use of way was investigated by running search queries for any element tagged as an adjective directly following adverbial way. This yielded tokens like way cool with the base form of the adjective in the absolute degree, and way better 'better by a great amount' with the inflected -er form of the adjective in the comparative degree, which drove the search for two variant patterns including periphrastic comparatives, i.e. $<w_{a y} y_{\text {amp }}$ more ADJ> and also <way ${ }_{\text {amp }}$ less ADJ>. Finally, relying on the OED's entry (s.v. way adv.3), I also searched for the pattern < way ${ }_{\mathrm{amp}}$ too ADJ> in which amplifier way modifies an adjectival phrase composed of an adjectival head modified by another amplifier (too). The results show that amplifier way collocates with (a few) descriptive (e.g. high, short) and mainly evaluative adjectives such as cool, good (better/worse), interesting, handsome, expensive, silly, harsh, painful, cheap(er), smart(er), wrong, awesome, cynical, overpriced, overrated. Many of the collocations occur only once in the corpus (e.g. way interesting, way silly, way catastrophic) while others (e.g. way big(ger), way too big, way cool(er), way too easy) are more frequent - up to 18 tokens of e.g. way (too) big(ger).

Green's Dictionary of Slang dates back the amplifier use of way in American English to the late nineteenth-early twentieth century. One of the examples illustrating its use as "general intensifier" 'very, extremely' is provided in (21): ${ }^{11}$

(21) Got a heavy date and I'm way late. [Green's Dictionary of Slang s.v. way adv., 1932] $]^{12}$

31

The earliest attestations of the construction $<w a y_{\text {amp }} \mathrm{ADJ}>$ in COHA also go back to that time, as shown in (22) and (23):

(22) You'll excuse me for sayin' you're rather delayin' your chance to insure your own [safe return]! For we're way worn and weary, your style isn't cheery, we've had quite enough of your game. [COHA, The Writings, 1896]

(23) Pass over them documents for Cherokee Hall, an' don't hold out nothin' onto us. We-alls is' way too peevish to stand any offishul gaieties to-day. [COHA, Wolfville, 1897]

Note, however, that the search for the variant constructions $<w_{a y} y_{\mathrm{amp}} \mathrm{ADJ}_{\mathrm{cmp}}>$ and $<w a y_{\text {amp }}$ too ADJ> returned only very few hits until the late twentieth century. One example is provided in (24):

(24) Miss Devlin in school had told them all that the sky was so many many miles away that everything in the sky looked very small, when it was really very very big, and the sky was way bigger than the earth. [COHA, Random House 1981, 1936] 
The frequency of the construction $<w_{a y}{ }_{\text {amp }} A D J_{a b s[o l u t e]}>$ is slightly higher over the same time period, but all in all the variant amplifier way-constructions show a low token frequency until the 1990s, as illustrated in Figure 1.

Figure 1. Relative frequency of the amplifier way in pre-adjectival position in $\mathrm{COHA}$ (per million words)

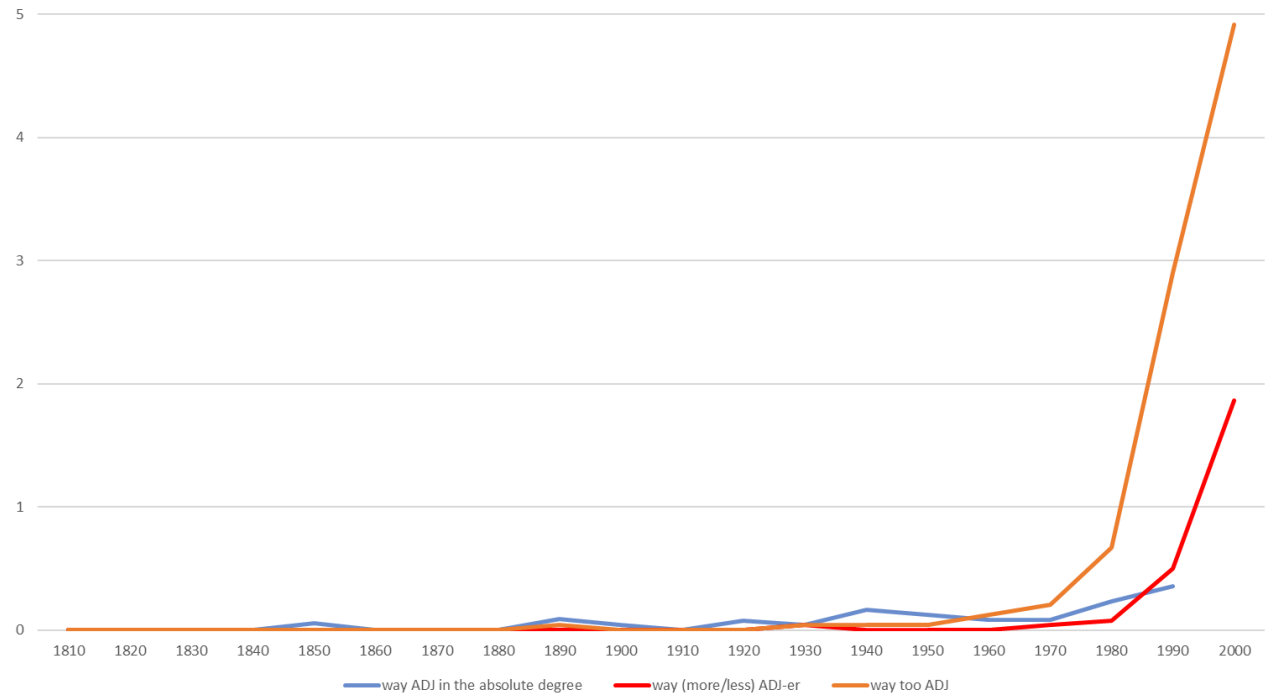

Early tokens could nonetheless be regarded as innovative precursors of a construction which then took off in the late twentieth century, especially in the form of <way ${ }_{\text {amp }}$ too $\mathrm{ADJ}>$, and, to a lesser degree, $<w a y_{\text {amp }} \mathrm{ADJ}_{\mathrm{cmp}}>$. Note for that matter that there are only two tokens of the pattern <way ${ }_{\text {amp }}$ less ADJ> in COHA; by contrast, the search for <way ${ }_{\text {amp }}$ more ADJ> yielded 28 results. In what follows (see Section 2.2.3., in particular) I will look into the kind of contexts which may have favoured the development of the specific constructions <way ADJ-er $>$, <way more $\mathrm{ADJ}>$, and $<w_{a y} y_{\text {amp }}$ too $\mathrm{ADJ}>$.

\subsection{Origins and development of the degree meaning}

What follows is an attempt to reconstruct the paths of (semantic) development of the amplifier way in American English from source constructions involving different uses of way. For this purpose, I discuss some of the historical data presented in Table 1 (in Section 1), and examine the contexts of use of the constructions that may have shaped the degree meaning until the 1990s, when the amplifier function of way seemed wellestablished (see Figure 1 in Section 2.1.).

\subsubsection{Spatial origins}

The starting point of this historical investigation was the possibly spatial origin of amplifier way which is said to derive from adverbial (a)way (Kirchner [1955]; Bolinger [1972]; Méndez-Naya [2012:369]; King [2016]). King [2016], in particular, seems to establish a historical connection between the earlier (originally and chiefly American English) spatial pattern $<w_{a y}{ }_{\text {adv }}$ PREP/ADV spatial $>$ (see OED s.v. way adv.2a and 2b; s.v. 
away adv.9b) illustrated in (25), and the more recent amplifier micro-schema <way ADJ>: 13

(25) There's Patrick, my brother, way over in Ireland -- the last time I saw him I wasn't taller than that butter firkin. [COHA, Little Ferns for Fanny's Little Friends, 1850]

The modifying function of way in both constructions supports this hypothesis - in part at least. Evidence will be provided later of an intermediate stage in the evolution of the micro-schema $<w a y_{\text {adv }}$ PREP/ADV spatial $>$ which could account for the further expansion (Himmelmann [2004]) of adverbial way to other types of modifiers than particles, especially to adjectival collocates.

Before addressing this issue, one needs to look into the origin of adverbial way in the construction illustrated in (25) to understand its possible historical semantic link with the micro-schema $<w a y_{\text {amp }}$ ADJ> (see infra for a discussion of the kind of mechanism of semantic change which might be involved). The OED (s.v. way adv.1) observes that adverbial way is probably an aphetic form of away, i.e. the adverb has lost the unstressed vowel at the beginning. As shown in (26), away can occur in the same type of micro-schema as way in (25):

(26) [I]ts a present to me, says I from Starks \&; Co., away up in York State, on the Black River. [COHA, The Select Letters of Major Jack Downing, 1834]

In this construction, away mainly "modif[ies] adverbs of distance or time, as away back, away behind, away down, away up, emphasizing the extent, remoteness, etc., involved" (OED s.v. away adv.9b). In the micro-schema < way ${ }_{\text {adv }}$ PREP/ $\mathrm{ADV}_{\text {spatial }}>$, way 'at or by a considerable distance, far' (OED s.v. way adv.2) is thus indeed very close to away in the construction <away PREP/ADV spatial . Evidence is provided in (27) and (28) which supports the idea that $<w a y_{\text {adv }}$ PREP/ADV spatial $>$ derives from <away PREP/ADV ${ }_{\text {spatial }}>$ as they show a possible intermediate stage in the phonological erosion of away which takes the form 'way:

(27) A wicked man was coming to take little Harry away from his mother, and carry him 'way off in the dark. [COHA, Uncle Tom's Cabin,1852]

(28) "Now you see," said the boatswain, "just so sure as you have gentle breezes from the south'ard, you'll have a thundering Levanter at the back of 'em." "Yes, yes," said a tar, "I know that to my sorrow. I was up the Straits last v'y'ge, 'way up to Smyrna and Zante, after reasons, and we ketch'd one of these thundering Levanters, and was druv' way to $\mathrm{h}$-- 11 , away up the Gulf of Venus." [COHA, An Old Sailor's Yarns, 1835]

The fact that the full form away (away up the Gulf of Venus) in (28) occurs alongside the phonologically reduced one 'way ('way up to Smyrna and Zante) is particularly enlightening. In (29) and (30), the construction <way PREP/ADV spatial $>$ is probably no longer interpreted as a phonological variant of $<$ away PREP/ADV spatial $>$. A constructional change appears to have taken place at the morpho-phonological level which makes it possible to analyze <way PREP/ADV spatial $^{>}$as a new construction, with way taking on a new function, namely modifier of spatial particles: 
(29) "Oh mamma, see, see!" cried Grace, more than half frightened at the sight; "papa has gone away, way out, and Maxie with him." [COHA, Elsie at Nantucket, 1884]

(30) "Where are the purple notches?" the doctor asked. "See yonder, away, way off?" Thaine pointed toward the misty southwest horizon where three darker curves were outlined against a background of pale purple blending through lilac up to silvery gray. [COHA, Winning the Wilderness, 1914]

41 in Section 1; see also OED s.v. way adv. 2a and 2b), may result from repetition of the pattern <'way ${ }_{\text {adv }}$ PREP/ADV spatial $^{>}$. Table 1 in Section 1 shows a significant increase in its frequency from the second half of the nineteenth century onwards. ${ }^{14}$ The fact that it was well-entrenched by the time way developed into an amplifier in the 1990s supports the assumption that this spatial construction could have been one of the sources of development of the micro-schema <way ${ }_{\text {amp }} \mathrm{ADJ}>$, at least in case of a semantic relationship between the two (see infra). As mentioned in Section 1, 17 spatial particles were found as collocates of way in this micro-schema.

The same spatial particles were found in collocation of the phrases a long way(s), a good way $(s)$ or a great way(s) in the other spatial pattern investigated, i.e. $<a$ long/good/great way(s) PREP/ADV spatial $^{2}$, which is illustrated in (31):

(31) The minister grew comparatively calm. His eyes, however, were soon greeted by a little, glimmering light, which, at first a long way off, was approaching up the street. [COHA, The Scarlet Letter, 1850]

43

As mentioned above, the OED observes that the noun phrases a long way(s), a good way(s), a great way(s), which are used adverbially, are found in later use in the reduced form $a$ way(s) (OED s.v. way n. 12b), just like a little way(s). Example (32) is one of the tokens retrieved of adverbial $a$ way (s) in COHA, from the second half of the nineteenth century onwards:

(32) So this is Bob Morton's law-office, is it? How Bob has got up in the world. Why! when I left home, his office was a way up in the loft of an old hulk of a house, down by the wharf. [COHA, The Tempter, 1871]

There is no specific mention in the OED that the phrase a way expresses a considerable rather than a little distance - as a little way(s), for instance, does - but the OED seems to suggest that this is so by referring in the same entry (OED s.v. way n. 12b) to the use originally in American English - since the mid-nineteenth century - of the phrase a ways which indicates 'a considerable or not insignificant distance' (OED s.v. way n. P3b). Note for that matter that about $40 \%$ of the patterns $<a$ way $(s) \operatorname{PREP} / \mathrm{ADV}_{\text {spatial }}>$ found in COHA clearly express a not insignificant distance through the use of quite as modifier of a way, as shown in (33):

(33) He watched them until he had floated quite a way below, when he began to hope that they had given up their designs upon him, and he might make his way back to his friends upon the island in safety. [COHA, Adrift in the Wilds, 1887]

45

But it is difficult to consider that the construction $<w_{a y}{ }_{\text {amp }} A D J>$ or even the microschema $<w a y_{\text {adv }}$ PREP/ADV spatial $>$ originate from the pattern $<a$ way(s) PREP/ADV spatial 
since it shows an overall low token frequency, with only scattered uses until the 1880s at least (see Table 1 in Section 1), while the early uses of the micro-schema <way ${ }_{\text {adv }}$ PREP/ADV $V_{\text {spatial }}>$ date back to the 1830 s. However, uses of $<a$ way(s) PREP/ADV spatial $_{\text {ind }}$, together with the micro-schema $<a$ long/good/great way(s) PREP/ADV spatial $>$ from which the former is derived and which has a much higher token frequency (see Table 1), may have reinforced the heightening effect of $<w a y_{\text {adv }}$ PREP/ADV $\left.{ }_{\text {spatial }}\right\rangle^{2}$.

What needs to be addressed now is the question of the mechanism of change from the spatial reading 'at or by a considerable distance, far' (OED s.v. way adv. 2a and $2 \mathrm{~b}$ ) of the construction $<w a y_{\text {adv }}$ PREP/ADV spatial $_{2}>$ to the degree meaning of $<w a y_{\text {amp }}$ ADJ $>$ in PDE. King's [2016] study provides a preliminary answer. The author focuses on the change from certain types of adverbs to certain types of intensifiers, including (a)way. What is of interest for the present paper is not so much King's [2016] discussion of what determines that way has become an amplifier and not, e.g., a downtoner (Quirk et al. [1985: 590]), as the fact that the author considers the amplifier way to be derived from adverbial spatial (a)way, and analyzes the semantic change in terms of metaphorical transfer. On the basis of the PATH image-schema used to depict the semantics of away, and the metaphorical interpretation of a scale in terms of a path (Johnson [1987: 122-123]), King argues that an increase in distance (away) is reinterpreted as a rise in degree. Example (34) leaves no doubt as to the possibility for the string <way PREP(/ADV)> to develop a (metaphorical) degree meaning:

(34) In Hollywood colossal is several degrees under supercolossal and supercolossal is way beneath terrific. [COHA, Murder on the Face of It, 1940; emphasis mine]

Now the question is what contexts of use may have triggered host-class expansion (Himmelmann [2004: 32]), i.e. construction-internal expansion of the class of elements adverbial way can collocate with. More precisely, what may have triggered the kind of constructional change (see e.g. Traugott \& Trousdale [2013]; Traugott [2015]) consisting in the expansion of adverbial way to adjectival collocates in the pattern <way ${ }_{\text {amp }} \mathrm{ADJ}>$ ? Quite importantly, the data in COHA show that the semantic and pragmatic contexts of use of the micro-schema $<$ way $_{\text {adv }} \mathrm{X}>-$ whereby $\mathrm{X}$ is any type of modified item - are expanded. In particular this semantic-pragmatic context expansion (Himmelmann [2004: 32-33]) takes the form of a gradual metaphorical change in the semantics of the prepositional or adverbial collocates of way in the pattern <way ${ }_{\text {adv }}$ PREP/ADV >. While these collocates take on an original spatial - whether allative, i.e. "movement towards a location", or locative - meaning in early uses of the construction, as in "papa has gone away, way out" in (29) above, they start to show not only temporal but also even more abstract meanings which sometimes make the string <way adv $_{\text {PREP/ADV }>\text { semantically }}$ akin to the pattern <way amp $A D J>,{ }^{15}$ as in (35) to (37), and may thus pave the way for the expansion of the construction $<w a y_{\text {adv }} \mathrm{X}>$ to adjectival collocates:

(35) "In such a matter as this, the opinion of an expert is everything. I am going to have one of the principal musicians of the town go and try them all, and tell me which we ought to have." "And while he's about it," said Alice, "you might ask him to make a little list of some of the new music. I've got way behind the times, being without a piano so long." [COHA, The Damnation of Theron Ware, 1896] 
(36) It will surprise everybody and cause big drop [...]. A drop only of about six points. This is one of the highest averages for the (September) month ever known. Is way above the ten-year average. [COHA, New York Times, 1905] (37) If we got outside we would freeze to death, as it was way below zero. [COHA, New York Times, 1927]

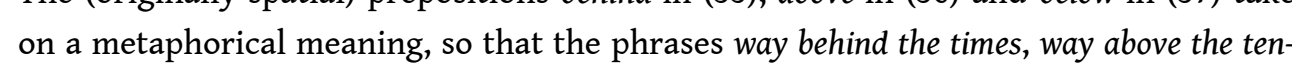
year average and way below zero can be paraphrased as 'way outdated', 'way superior to the ten-year average' and 'way inferior to zero', respectively. Interestingly, in the informal phrase way off base 'completely mistaken' in (38), it is the string off base, which is originally an instantiation of <preposition + noun (phrase)>, which receives a metaphorical interpretation, so that the meaning of the whole is akin to adjectival meaning ('mistaken'):

(38) And every time he fails he takes it out on me because I didn't get to Elmer sooner. But you can see perfectly well he's way off base, trying to make out I could have done a thing to prevent what happened. [COHA, The Aggravation of Elmer, 1955]

Uses of the construction $<w a y_{a d v}$ PREP/ADV $>$ with various abstract metaphorical interpretations of the prepositional or adverbial collocates, or the string <preposition + noun (phrase)>, such as those illustrated in (35) to (38) above, occur as from the late nineteenth-early twentieth century, and could thus be considered as intermediate stages in the development of the more recent adjectival pattern $<w a y_{\text {amp }} A D J>$ out of the original spatial construction $<w_{\text {adv }}$ aREP/ADV spatial $_{\text {al }}$.

The data in COHA show the same kind of constructional change through the semanticpragmatic expansion of the construction $<a$ long/good/great way(s) PREP/ADV >, which is illustrated in examples (39) to (42):

(39) When he was yet a great way off, his father saw him, and had compassion, and ran, and fell on his neck, and kissed him. [COHA, Female Scripture Biographies, 1817]

(40) You say the negro blood is mighty poor stuff, and the race is a long way behind ours. [COHA, What Answer? 1868]

(41) The day will come, I believe, when Mr. Eakins will be rated, as he deserves, far above the painters of mere pretty effects, and a good way above even men of similar artistic skill who devote themselves to less characteristic and less vital themes. [COHA, The New York Art Season,1881]

(42) "You know it all better than I do. I'm only trying to say that I get some kind of joy out of being near people like that, out of having some reason for doing anything that they do. That must be why I go to market like this, for of course there is no other reason." "Poor kid," said Mark, looking down at her with tenderness. "What a long way off base you are." "And not you?" asked Jessie. "Certainly, sometimes. But I told you last night --" "Yes," she said. "I remember." "And I am much nearer to these people than you," he said. [COHA, East Side, West Side,1947]

While behind takes on its original spatial meaning in (39), behind in (40) and above in (41) do not; they are reinterpreted metaphorically, so that a long way behind and a good way above mean 'way inferior (to)' and 'way superior (to)', respectively. And just as "way off base" in (38) above was interpreted as 'completely mistaken', "a long way off base" in (42) expresses the same idea. Note, however, that the prepositions or adverbs which $a$ 
way(s) collocates with take on mainly a spatial meaning, sometimes a temporal one, but not the kind of metaphorical reading permitted by e.g. a long way behind in (40) above. The assumption put forward is that although the constructions < a long/good/great way(s) PREP/ADV > and <a way(s) PREP/ADV> are less likely to have been direct sources of development of the micro-schema <way ${ }_{\text {amp }}$ ADJ>, they could still have had an indirect impact on it - both with literal and metaphorical readings of the particles - thus enabling to reinforce the heightening effect of the construction $<w a y_{\text {adv }}$ PREP/ADV $>$ via metaphorization again. But while it is the notion of increase in distance captured by away in the spatial construction <away PREP/ $\mathrm{ADV}_{\text {spatial }}$ which is, by hypothesis, metaphorically reinterpreted in terms of high degree in the construction <way ${ }_{\text {amp }}$ ADJ> (see King [2016]), it is the notion of long distance denoted by the phrases a long/good/ great way which is thus reinterpreted.

\subsubsection{The adverbial phrase in every way}

When searching for the amplifier micro-schema examined in Section 2.1., I came across a pattern showing way as part of a phrase functioning as modifier of an adjective, i.e. $<$ (in) every way ADJ>. The OED cites the use of nominal way in adverbial phrases such as (in) any way which indicate "a respect or particular in which things can be judged or compared" (OED s.v. n. 21), but not the specific phrase (in) every way. I set out to explore the latter as a potential source of development of the amplifier micro-schema because of formal and semantic similarities. I thus searched for the patterns < (in) every way ADJ> but also <(in) every way more/less/too ADJ> in order to establish potential parallels with the different forms of the amplifier patterns, i.e. $\left\langle w a y_{a m p} A D J_{a b s}>,<w a y_{a m p} A D J_{c m p}>\right.$, and $<$ way $_{\text {amp }}$ too ADJ> (see Section 2.1.). I also examined the pattern <ADJ in every way $>$. The searches returned a total of 604 tokens, fairly distributed (see Table 1 in Section 1) between the pattern <(in) every way (more/less/too) ADJ>, with the phrase (in) every way in premodifier position of the adjectival head, and the pattern $<$ (more/less/too) ADJ (in) every way>. Note that just as I retrieved only two tokens of the construction <way less $\mathrm{ADJ}>$, the search for the patterns < (in) every way less ADJ> and <less ADJ (in) every way> yielded only two results too. I will therefore no longer mention less when referring to the constructions < $<a y_{\text {amp }} \mathrm{ADJ}_{\mathrm{cmp}}>$.

The examination of the whole dataset revealed that the original reading 'in every respect (more/too) ADJ'/'(more/too) ADJ in every respect', which is illustrated in (43), could in specific contexts give rise to an inference (Traugott \& Dasher [2002]) of high degree, as in (44):

(43) The whole cycle is given in the last twenty years of Republican rule here at home, when the representatives of the party resolved to hold on to office after they had done their work, for all sorts of patriotic reasons, but at bottom because they found it profitable and pleasant to hold on. They were forced to pay roundly for the privilege; the possession was assured to them only by concessions of the largest kind to importunate interests. This was bad, bad in every way; in morals, because the honor and profit of administering the people's trust should be conferred by an honest majority of the people, and not bought of an interested class; as practical politics, because the ally is sure to sell out to the highest bidder whenever it becomes safe to do so. [COHA, Reform: The Democratic Machine, 1886]

(44) He had said, as plainly as he could look it, that he didn't want me here; that I was only a trouble to him; that I made him unhappy by remaining; that 
he would be much better in every way if I were gone. [COHA, The Last Woman, 1909] vast majority of the 175 adjectives collocating with (in) every way in the constructions $<$ (more/too) ADJ (in) every way> and <(in) every way (more/too) ADJ> in COHA are gradable (evaluative) adjectives, e.g. good, bad, strong, beautiful, attractive, fine, great, wrong, uncomfortable, interesting, big, pleasant, poor, vicious, important, handsome, magnificent, stupid. One condition was thus met for the phrase (in) every way to turn into a degree modifier. Secondly, and quite relatedly, about $15 \%$ of the examples of the two constructions show the adjectival head being premodified by degree modifiers like so, very, completely, utterly, etc. This is the case in (44) where much intensifies the meaning of better. Another characteristic of a bridging context possibly giving rise to the meaning of high degree in the constructions < (more/too) ADJ (in) every way> and < (in) every way (more/too) ADJ> is the use of similar degree modifiers in the larger context of the constructions, as in (45) or (46):

(45) Is it so very wonderful that Abby should grow? To be sure -- certainly not -- she was very fair when I saw her last -- when I left this part of the world, I mean. Very -- So upright, and so graceful and free in her carriage... Free in her carriage? For a child, I mean -- so modest, and so remarkable in every way -so attentive, so quiet. [COHA, Rachel Dyer: A North American Story, 1858; emphasis mine]

(46) The Place Vendome is small, surrounded by high houses, and the stately Column seems dwarfed by them. But for its historic interest, and especially that of the material employed in its construction, I should not regard it very highly. Far better placed, as well as more majestic and every way interesting, is the Obelisk of Luxor. [COHA, Glances at Europe in a Series of Letters from Great Britain, France, Italy, Switzerland \&c. D, 1851; emphasis mine]

Although the OED does not report the use of (in) every way as degree modifier, some examples do suggest that its high degree meaning may even have been semanticized at some point. In (47) and (48), the literal meaning of the phrase in every way is apparently not available:

(47) When you combine quality with style, you will be a better shopper. You will then have a garment which will be finer in every way as far as material and workmanship are concerned. [COHA, Your Clothes and Personality, 1937]

(48) The cabin stood in a valley, or canon, in the shadow of gigantic pinetrees, rising straight as a flagpole to the altitude of nearly two hundred feet. They were forest giants, impressive in their lofty stature, and Ben regarded them with wonder and awe. They were much smaller in every way than the 
so-called big trees to be found in the Calaveras and Mariposa groves. [COHA,

The Young Explorer, 1880] high degree, especially in very expressive contexts such as illustrated in (46) above in which the speaker/writer makes abundant use of degree modifiers in the immediate context. "Analogy with other similarly behaving degree modifier micro-constructions [...] which were well established by that time" (Trousdale [2012:182]) may thus have reinforced this type of inference (see Section 2.2.4. for a discussion of the role analogy is likely to have played in the development of the micro-schema $<w a y{ }_{\text {amp }} \mathrm{ADJ}>$ ).

61 Secondly, in about 33\% of the tokens retrieved the preposition in is omitted (see examples (46) and (49) above). Examples (51) and (52) illustrate the use of every way (without the preposition in) combined with its use in premodifier slot:

(51) Nothing would seem to be plainer, than that Aurelian spared Zenobia because she was a woman; because she was a beautiful and every way remarkable woman. [COHA, Letters of Lucius M. Piso, from Palmyra, to his Friend Marcus Curtius at Rome, Volume 2, 1837]

(52) The berries were not only much more numerous than the year before, but they were every way larger and finer. [COHA, Needle and Garden, 1865]

might assume that every way is a morphologically reduced version of in every way and that the phrase moved to premodifier slot over time, and then consider these as 
possible signs of constructional change. But the data show that every way was in fact more frequent than in every way in the early nineteenth century, and this continues until the late 1860s. The full form in every way then becomes in its turn much more frequent than every way both in <in every way (more/too) $\mathrm{ADJ}>$ and <more/too ADJ in every way>, and this situation continues until the 2000s. The time gap between the first half of the nineteenth century and the late twentieth century, when the token frequency of amplifier way took off, suggests that the phrase every way with the preposition in omitted probably had little impact on the syntactic development of the amplifier. However, the persistence of the high degree meaning associated with (in) every way both in premodifier and postmodifier slot could be considered as a sign of semantic inheritance. It is in fact noteworthy that the use of both every way and in every way in premodifier position falls dramatically in the early twentieth century, as shown in Figure 2, that is to say at the time when way started to be used as amplifier (see Figure 1 in Section 2.1.), and that there are in COHA no tokens at all of the pattern <every way (more/too) ADJ> and only 5 of <in every way (more/too) ADJ> over the 1980-2009 period. Recall that, as shown in Figure 1 (in Section 2.1.), the frequency rate of <way ${ }_{\text {amp }}$ ADJ> really takes off around the 1990s. This might suggest that it has replaced the phrase every way as premodifier of adjectival collocates.

Figure 2. Relative frequency of the pattern < (in) every way ADJ> in COHA (per million words)

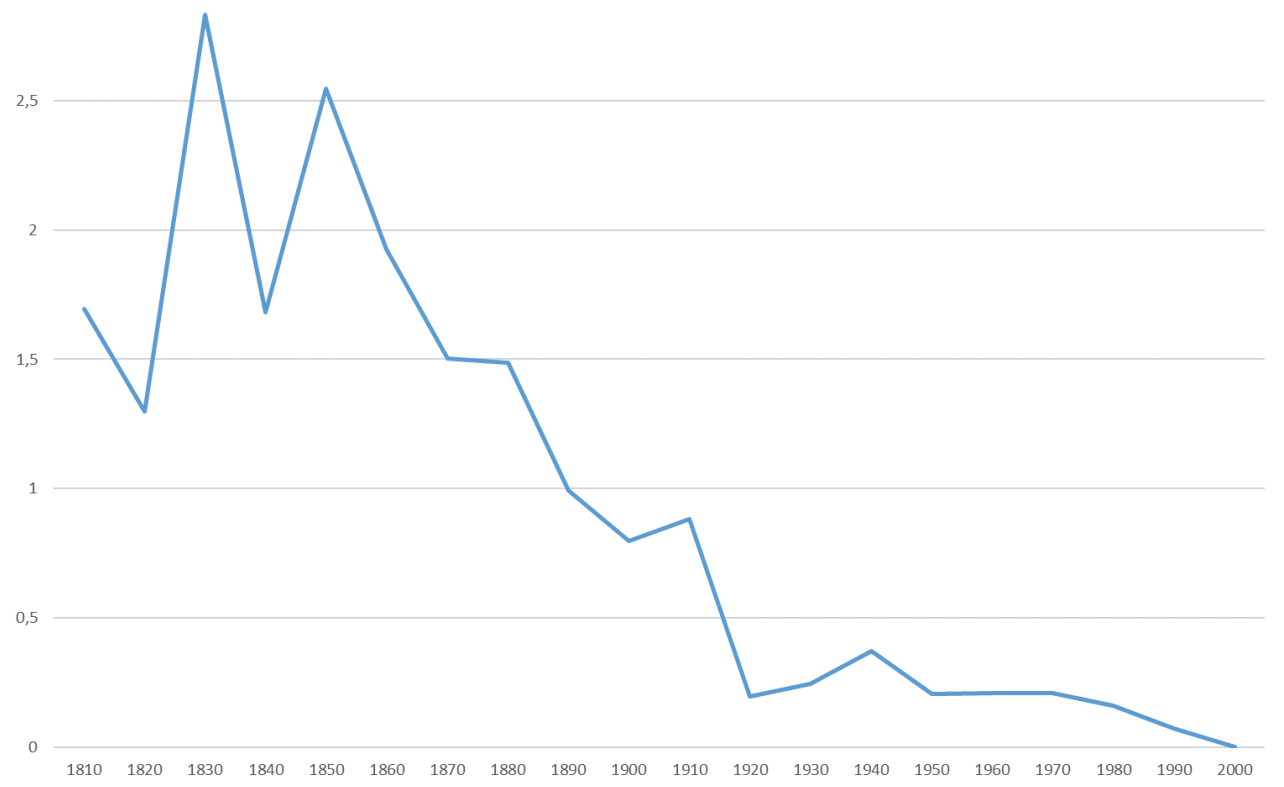

63 It is noteworthy that while the search for the specific pattern $<w a y_{\mathrm{amp}} \mathrm{ADJ}_{\mathrm{cmp}}>$ returned only four hits - with the inflected or periphrastic form of the comparative - up until the 1990s (see Table 1 in Section 1), the search for the pattern < (in) every way $\mathrm{ADJ}_{\mathrm{cmp}}$ > did return many more results ( 40 tokens) before it fell into disuse in the 1980s. Since the pattern < (in) every way $\mathrm{ADJ}_{\mathrm{cmp}}>$ may also have invited the inference that 'if something or someone is more $\mathrm{X}$ in every way, it or s/he is X to a high degree', one could assume that this specific pattern may have favoured the development of the construction <way amp $A D J_{c m p}>$ as from the 1990s. By contrast, only two tokens were found of the construction <(in) every way too ADJ> in COHA, which means that this specific pattern cannot account for the rise and, later, the spectacular growth of the 
construction <way too ADJ> from the 1980s onwards. Therefore, other contexts of use of way in collocation with too will have to be looked into.

Two other way-based patterns recorded in the OED might bear out the assumption that the amplifier way is, historically, semantically related to the phrase (in) every way. These are <in no way $\mathrm{ADJ}>$ and <no way(s) ADJ> originally 'in no manner or not at all ADJ' (OED s.v. way n. and int. P6; no way adv.A), illustrated in (53) and (54):

(53) The scenery was not without beauty; wooded hills of gentle slope every where bordered the river; and its islands and alluvions, still of considerable extent, are no way inferior to the lands of the Ohio. [COHA, Nuttall's Journal, 1827]

(54) They were burned in the furnace downstairs without being counted or checked up, and without witnesses save a clerk named Frank D. Leland of Olean, who was in no way legally responsible for their care. [COHA, New York Times, 1907]

Although the specific meaning of (in) every way obviously differs from that of (in) no way, the two patterns share an original manner reading as well as a degree function. This common feature supports the hypothesis that the development of <way ${ }_{\text {amp }}$ ADJ> was influenced, in part at least, by the existence of other way-constructions expressing degree which preceded it in time. A quick look at the first ten adjectives collocating with (in) no way in $\mathrm{COHA}^{16}$ suggests that the pattern <(in) no way ADJ> is used as from the early nineteenth century, just like the pattern < (in) every way ADJ>. Among the tokens retrieved there are also a few examples of the pattern <no ways ADJ>, which also date back to the nineteenth century, according to the data in COHA. One example is provided in (55):

(55) "Make yourself easy, madam," said he, "his lordship is no ways dangerous, I know him too well, and he knows me full as well." [COHA, The Tennessean, 1827]

In examples (53) to (55) no way(s) 'not to any extent, not at all' functions as a minimizer. It is the negative no which turns no way(s) into a negative maximizer (Quirk et al. [1985:597]) scaling downwards, in other words a minimizer. One could therefore assume a historical connection between the older negative maximizer no way(s) and the more recent amplifier way which scales upwards, at the opposite end of the scale, with the constructions < (in) every way $\mathrm{ADJ}>$ and $<\mathrm{ADJ}$ (in) every way> half-way along the path, as semantic precursors of $<w_{a y} y_{\text {amp }} \mathrm{ADJ}>.^{17}$

\subsubsection{Analogization and paradigmatization}

67 In this section I propose that analogization, i.e. the mechanism of analogy leading to the development of a new micro-schema on the basis of an exemplar model, is most probably involved in the development of the amplifier way in American English. Recently, analogy-driven changes have received a great deal of attention (see e.g. Fischer [2007], [2008], [2009]; De Smet [2013]; De Smet et al. [2018]). In analogy, the behaviour of one expression is modelled after the behaviour of another which it resembles (Antilla [2003]; Fischer [2007]; De Smet [2013]). Fischer [2009: 16] argues that one needs to consider changes in terms of the network that the construction/item operates in, and that the influence of paradigms in the grammar system is likely to be stronger than the influence of context (Fischer [2013:521]). This idea has gained 
ground in the wake of recent research on constructional grammaticalization (e.g. Traugott [2007], [2008a], [2008b], [2015]; Trousdale [2008], [2010], [2012]), and more generally constructionalization (Traugott \& Trousdale [2013]). As Traugott [2019:130] observes, "if, as DeSmet (2013) proposes, "language users are tireless at inferring regularities from usage' (DeSmet 2013: 8), analogy will necessarily be a crucial factor in the development of new expressions". In this paper I argue that analogy and analogization most certainly played a crucial role in the emergence of the construction $<$ way $_{\text {amp }} \mathrm{ADJ}$.

In PDE, the constructions $<w a y_{\text {amp }} \mathrm{ADJ}_{\mathrm{cmp}}>$ and $<w a y_{\text {amp }}$ too $\mathrm{ADJ}>$ are very close to the constructions <much/far amp $A D J_{c m p}>$ and <much/far amp too ADJ>. In (56), "way bigger" could thus be paraphrased as far bigger, and in (57) "way older" is rephrased as "much older" in the following context:

(56) Miss Devlin in school had told them all that the sky was so many many miles away that everything in the sky looked very small, when it was really very very big, and the sky was way bigger than the earth. [COHA, Random House, 1981]

(57) "So, how old are you?" Amy asked suspiciously. "In Earth years?" Dorothy smirked. "Way older than you." Small surprise, Dorothy acted much older than anyone Amy knew, except maybe Dad. [COHA, Kansas, she says, is the name of the star, 2006]

The amplifiers much and far differ from way in terms of register (among other things). Much occurs in formal contexts, far in both formal and informal ones, and way is considered to be informal in the constructions $<w a y_{\text {amp }}$ ADJ $>$ and $<w a y_{\text {amp }}$ too ADJ $>-$ and slang when modifying an adjective in the absolute degree, e.g. way cute (OED s.v. way adv.3). In (56), way seems to be best suited because of the conversational tone of the passage and the repetitions ("so many many miles away", "really very very big") which, like "way bigger", suggest a high degree of expressivity.

The focus here will be on the constructions $<f a r_{\text {amp }} \mathrm{ADJ}_{\mathrm{cmp}}>$ and $<f a r_{\text {amp }}$ too ADJ $>$ because far can also modify a spatial preposition or adverb, just like (a)way (see Section 2.2.1.), as shown in (58):

(58) Soon upon a mountain plain I gaz'd with wonder new. There high a castle rear'd its head: And far below a region spread [...]. [COHA, The Sylphs of the Seasons with other poems, 1813]

71 Examples of the pattern $<$ far PREP/ADV $\mathrm{Apatial}_{\text {' }} \mathrm{X}_{\text {spatial }}$ by a long distance' are found from the early nineteenth century onwards in COHA. The parallel between (a)way and far based on their function as modifiers of both spatial prepositions or adverbs, and adjectival heads, and the spatial meaning of adverbial far and (a)way explain why I took a closer look at the amplifier far-construction, which is illustrated in (59):

(59) The practice of dedicating children to God, is, we perceive, sanctioned by the usage of high antiquity; but, what is far better, it is conformable to reason and Scripture. [COHA, Female Scripture Biographies, 1817]

I propose that semantic analogization based on this construction may have been one of the factors of change steering the semantic development of the amplifier way. Semantic analogization is a mechanism of analogical extension (De Smet [2013: 65]) based on semantic similarity between syntagmatically related source and target constructions 
(De Smet [2013:69]). De Smet [2016] argues that in order for analogy to be able to operate, the analogical model needs to be accessible, which (among other things) depends on its degree of entrenchment. A comparison between the frequency of $<f a r_{a m p}$ $\mathrm{ADJ}_{\mathrm{cmp}}>$ and $<\mathrm{far}_{\mathrm{amp}}$ too $\mathrm{ADJ}>$ on the one hand, and $<w a y_{\mathrm{amp}} \mathrm{ADJ}_{\mathrm{cmp}}>18$ and $<w a y_{\mathrm{amp}}$ too ADJ> on the other, shows a sharp contrast between the two types of construction.

Figure 3. Relative frequency of the constructions $<f a r_{\text {amp }} A D J_{c m p}>$ and $<f a r_{a m p}$ too ADJ $>$ compared with $<$ way $_{\text {amp }} A D J_{c m p}>$ and $<w_{\text {amp }}$ too ADJ $>$ (per million words)

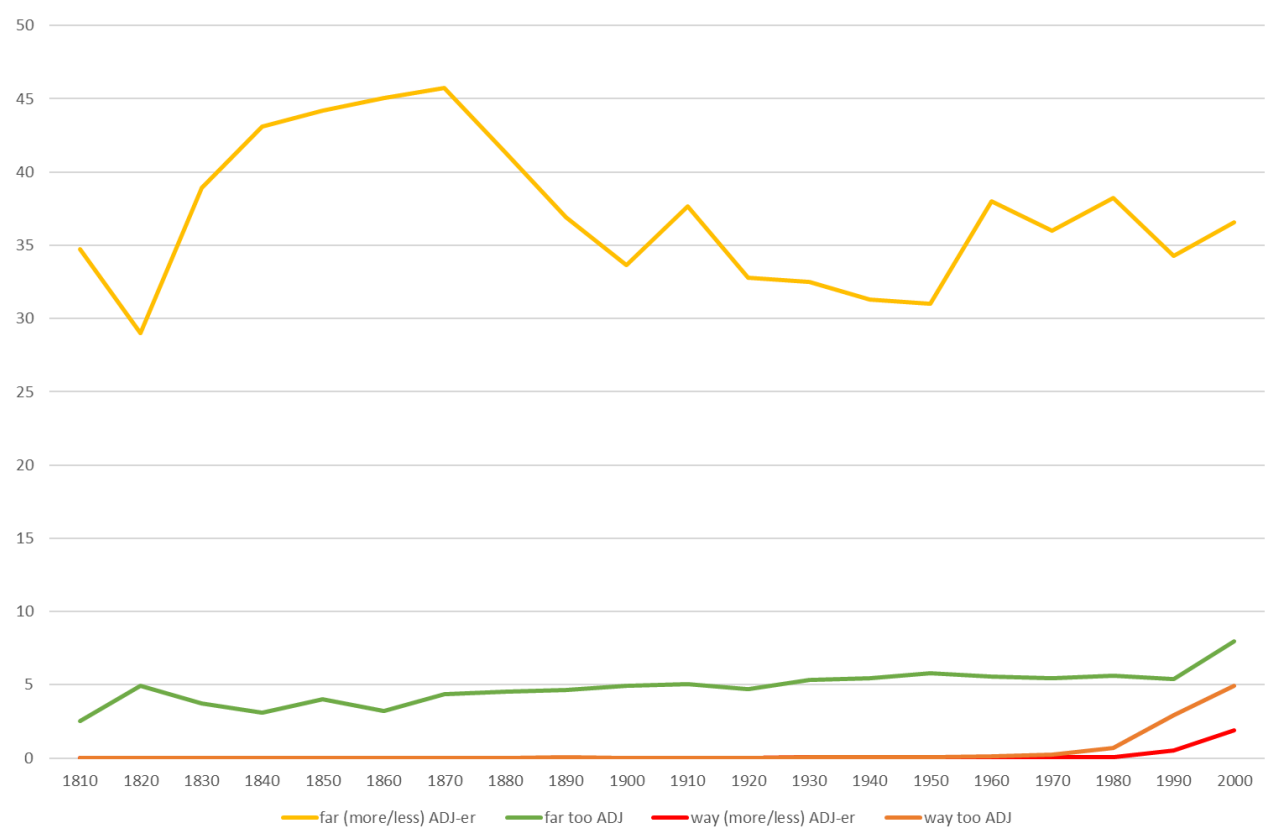

Figure 3 provides evidence of the much higher frequency rate of the amplifier farconstructions than the way-constructions from the early nineteenth century to - at least - the late twentieth century, by which time the frequency rate of the construction $<$ way $_{\mathrm{amp}} \mathrm{ADJ}>$ rose significantly (see Figure 1 in Section 2.1.) and may be interpreted as a sign of entrenchment. Taking discourse frequency as a proxy to entrenchment, I argue that since the constructions $<\mathrm{far}_{\mathrm{amp}} \mathrm{ADJ}_{\mathrm{cmp}}>$ and $<\mathrm{far}_{\mathrm{amp}}$ too $\mathrm{ADJ}>$ were well-entrenched when way started to show signs of development into an amplifier in the late nineteenth-early twentieth century (see Section 2.1.), they served as analogical templates for the development of the amplifier way. ${ }^{19}$ Similarly, the extant microschema $<$ far PREP/ADV spatial $>$ may have spearheaded the further development of the micro-schema $<$ way PREP/ADV spatial $>$, which is itself one of the possible triggers of the development of the degree meaning of way (see Section 2.2.1.). The co-existence in the English language of the micro-schemas $<$ far PREP/ADV spatial $>,<f a r_{\text {amp }} \operatorname{ADJ}_{\mathrm{cmp}}>$ and $<f a r_{\mathrm{amp}}$ too $\mathrm{ADJ}>$ most certainly drove some language users to use the innovative constructions $<$ way $_{\text {amp }} \mathrm{ADJ} \mathrm{cmp}>$ and <way amp $_{\text {too }} \mathrm{ADJ}>$ as (metaphorical) extensions of <way PREP/ $\mathrm{ADV}_{\text {spatial }}>$ on analogy with the (hypothetically metaphorical) extension of the microschema $<$ far PREP/ADV spatial $>$ to the micro-schemas $<f a r_{\text {amp }} A D J_{\text {cmp }}>$ and $<f a r_{\text {amp }}$ too ADJ $>$. If so, semantic and paradigmatic analogization are further causes of change in the development of the degree modifier constructions <way ${ }_{\mathrm{amp}}$ (more/too) ADJ(-er)>, alongside metaphorization (see Section 2.2.1.) and inferencing (see Section 2.2.2.). At least, one can hardly discard the assumption that the far-constructions favoured the 
spread of the (degree modifier) way-constructions in the community of American English language users.

There still remains to explain why the amplifier way, by contrast with far, can collocate with various evaluative adjectives in the absolute degree, such as cool in (60) (see Section 2.1.):

(60) On Christmas morning under the tree, Amanda is thrilled with her trendy new pair of Guess jeans and her Songbird Barbie doll. Joey thinks his new Nike cross-trainers are way cool, and he's in love with his Disney 101 Dalmatians jogging gear. [COHA, Santa's Sweatshop, 1996]

As mentioned above, the amplifier far pre-modifies adjectives in the comparative degree and adjectives in the absolute degree which are already pre-modified by amplifier too. Only a restricted set of adjectives in the absolute degree can occur with it without too being used as premodifier, e.g. different, preferable, inferior, superior, wrong, short, distant, remote, wide, adrift, astray, astern. Two examples are provided in (61) and (62):

(61) I attended my studies in school, with far different feelings and different motives, from what I had ever done before. [COHA, Memoir of Mrs Ann H. Judson, Late Missionary to Burmah, 1829]

(62) The implication was that the Kennedy set-up was far preferable to that at other airports like Rome's. [COHA, New york Times, 1985]

The amplifier way collocates with similar adjectives encapsulating the idea of a comparison between two entities ${ }^{20}$ - which, quite interestingly, also underlies the pattern <way/far ${ }_{\text {amp }} \mathrm{ADJ}_{\mathrm{cmp}}>-$ as shown, for instance, through the constructs way different (see Example (2) in the Introduction), way overcrowded, way overpriced or way overrated found in COHA, but it has expanded its collocational profile to a wider range of adjectives in the absolute degree, as evidenced by the results of the search query $<$ way $_{\text {adv }}$ ADJ> (see Section 2.1.) which yielded tokens like way cool, way rich, way cynical, way posh, way young, etc. Though the construction $<f a r_{a m p} A D J_{a b s}>$ was most probably an analogical model for the development of $<w a y_{\text {amp }} \mathrm{ADJ}_{\mathrm{abs}}>$, the fact that it shows a much lower type frequency than the construction <way ${ }_{\text {amp }} A D J$ abs $>$, with many fewer evaluative adjectives as possible collocates of far, suggests that other factors of change are involved. Indeed, the construction $<w a y_{\mathrm{amp}} \mathrm{ADJ}_{\mathrm{abs}}>$ also (partially) matches other preexisting degree modifier micro-schemas such as <very ADJ>, <so ADJ>, <really ADJ>, $<$ well ADJ> (for a study of these patterns, see e.g. Ito \& Tagliamonte [2003]; Tagliamonte \& Roberts [2005]; Breban \& Davidse [2016]). In the late twentieth and early twenty-first centuries the construction <way ${ }_{\text {amp }} \mathrm{ADJ}_{\text {abs }}>$ may thus have aligned its behaviour through attraction (De Smet et al. [2018]) not only to the construction $<f a r_{a m p} A D J_{a b s}>$, but also to the bigger constructional family of amplifiers modifying a wide range of adjectives in the absolute degree. Paradigmatic analogization, i.e. extension to an existing set of alternatives based on a "semantic, formal and/or distributional relation of similarity" (De Smet [2013:69]) could therefore be involved in the emergence of the degree modifier construction <way ${ }_{\text {amp }}$ ADJ> (see Aaron [2016] for similar conclusions concerning some degree modifiers in Spanish). 


\section{Summary of the findings and conclusion}

77 In the previous section, I identified several possible semantic sources and mechanisms or causes of change involved in the semantic development of the amplifier way. In the present section I provide a summary of the findings, and conclude not only that multiple source constructions may be at the origin of the constructionalization of the amplifier way and, more particularly, of its high degree meaning, but also that different mechanisms or causes of change may have interacted at different stages of its developmental path. It thus questions a simplistic linear development. The development of the amplifier construction is couched in terms of grammatical constructionalization, with special emphasis on "the architecture of construction grammar [which] demands thinking in terms of [...] not only individual substantive constructions but also abstract schematic ones" (Traugott [2015: 52]).

78 I first presented the construction $<w a y_{\text {adv }}$ PREP/ADV > as one of the possible sources of development of $\left\langle w_{a y} y_{\text {amp }}\right.$ ADJ>. I concurred with King's [2016] view that the metaphor HIGH DEGREE IS INCREASE IN DISTANCE (see King [2016]) hypothetically underlies the semantic development of the construction $<w_{a y} y_{\text {amp }} A D J>$, and I provided evidence of a constructional change in the pattern $<w a y_{\text {adv }}$ PREP/ADV $>$ through context expansion (Himmelmann [2004]) which may have further favoured the development of the amplifier construction by foregrounding the degree meaning. I also showed that the data in COHA suggest that the micro-schema $<w_{a y}$ adv PREP/ADV > may not only be historically related to away, but also to the constructions $<a$ long/good/great way PREP/ $\mathrm{ADV}_{\text {spatial }}>$ and, to a lesser degree, $<a$ way $(s)_{\text {adverbial }}$ PREP/ADV $\mathrm{Apatial}_{\text {s. }}>$.

Another possible source of semantic development of the amplifier way was identified, which is yet not rooted in the spatial domain, i.e. the adverbial phrase (in) every way. Evidence was provided of contexts in which a degree meaning arises inferentially out of the original manner reading, and other contexts in which the degree meaning even appears to be semanticized. I have also shown that an interesting parallel could be drawn between the sharp decrease in the frequency of the pattern <(in) every way ADJ> in the early twentieth century and the early uses of the construction <way ${ }_{\text {amp }}$ ADJ> at the same period.

80 A summary of the chronological development of the way-constructions investigated in this article is provided in Figure 4. 
Figure 4. A chronological overview of the amplifier way-construction and its possible sources in COHA

\begin{tabular}{|c|c|c|c|}
\hline \multirow[t]{3}{*}{1810} & 1850 & 1900 & 1950 \\
\hline & \multirow[t]{2}{*}{$w a y_{\text {adv }} \mathrm{PREI}$} & & \\
\hline & & $w a y_{\text {adv }}$ & orical \\
\hline \multicolumn{4}{|c|}{ a long/good/great way(s) $\mathrm{PREP} / \mathrm{ADV}_{\text {spatial }}$} \\
\hline & & a long & s) PRE \\
\hline & & $a w a y$ & \\
\hline
\end{tabular}

(in) every way $\mathrm{ADJ}$

$\mathrm{ADJ}$ (in) every way

$w_{\text {amp }} \mathrm{ADJ}$

81 The solid lines in Figure 4 indicate steady use of a pattern while the dotted ones point to (more) scattered uses. ${ }^{21}$

82 Note that the shift to amplifier function involves subjectification, i.e. the tendency of meanings to become increasingly based in the speaker's subjective attitude towards the proposition (Traugott [1995]; Traugott \& Dasher [2002]). The shift in meaning is not only from concrete (lexical) to more abstract (grammatical) meaning but also towards a more subjective meaning in the sense that it expresses high degree from the point of view of the speaker.

Language-internal factors provide additional clues as to what drove the semantic change of way. The prior existence within the larger degree modifier schema of the booster set composed of $<\mathrm{far}_{\mathrm{amp}} \mathrm{ADJ}_{\mathrm{cmp}}>,<f a r_{\mathrm{amp}}$ too $\mathrm{ADJ}>$, but also, for instance, <very/so/ really/well $\mathrm{ADJ}_{\mathrm{abs}}>$, and even $<$ far ${ }_{\mathrm{amp}} \mathrm{ADJ}_{\mathrm{abs}}>$, to a certain extent, was a most likely trigger for the change, which was based in semantic and paradigmatic analogization. I argued that the far-constructions played a central part in this process of analogization considering the semantic and syntactic similarities between far and (a)way, two spatial adverbs which can modify a spatial preposition or adverb. The higher frequency rate of $<$ way $_{\text {amp }} \mathrm{ADJ}_{\mathrm{cmp}}>$ and $<$ way $_{\mathrm{amp}}$ too $\mathrm{ADJ}>$ in $\mathrm{PDE}$ as compared to < way ${ }_{\mathrm{amp}} \mathrm{ADJ}_{\mathrm{abs}}>$ could in fact be related to the high frequency rate of $<f a r \mathrm{ADJ}_{\mathrm{cmp}}>$ and $<$ far too $\mathrm{ADJ}>$ (see Table 1 in Section 1). Still, further research is needed to account for the fact that it is the construction < way ${ }_{\mathrm{amp}}$ too $\mathrm{ADJ}>$ which is much more frequent than $<$ way $_{\mathrm{amp}} \mathrm{ADJ}_{\mathrm{cmp}}>(\mathrm{NF}=$ $0,6$ vs. 0,2$)$ whereas the pattern $<f a r_{\text {amp }}$ too ADJ $>$ is far less frequent than $<f a r_{\text {amp }} A{ }_{\mathrm{cmp}}>$ $(\mathrm{NF}=5,1$ vs. 36,9$)$.

The study of the amplifier far-constructions brings us back in turn to the hypothetical spatial origin of way, showing how metaphorization and analogization - not only on the model of < far ADJ> but also < far PREP/ADV> - may have been intertwining mechanisms or causes of change. But the fact that amplifier way has a large collocational profile, modifying adjectives both in the comparative and the absolute degree, including a 
wider range of adjectives in the absolute degree than far (way rich, way old; ${ }^{*}$ far rich, ${ }^{*}$ far old), suggests that analogization on the model of $\left\langle f a r_{\text {amp }} \mathrm{ADJ}_{\mathrm{cmp}}>\right.$ and $\left\langle f a r_{\text {amp }}\right.$ too ADJ $>$ only gives part of the picture of the development of the construction $<w a y_{\text {amp }} A D J>$ at the macro-level. This now brings us back to the pattern <(in) every way ADJ> which showed a wide range of evaluative adjectives involved, whether in the absolute or the comparative degree. The amplifier way may thus have inherited (part of) its collocational profile from it.

Figure 5 represents a constructional network of the different constructions that might at some point have favoured the semantic development of the amplifier wayconstruction.

Figure 5. A constructional network of the hypothesized sources of development of the micro-

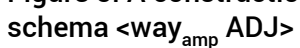

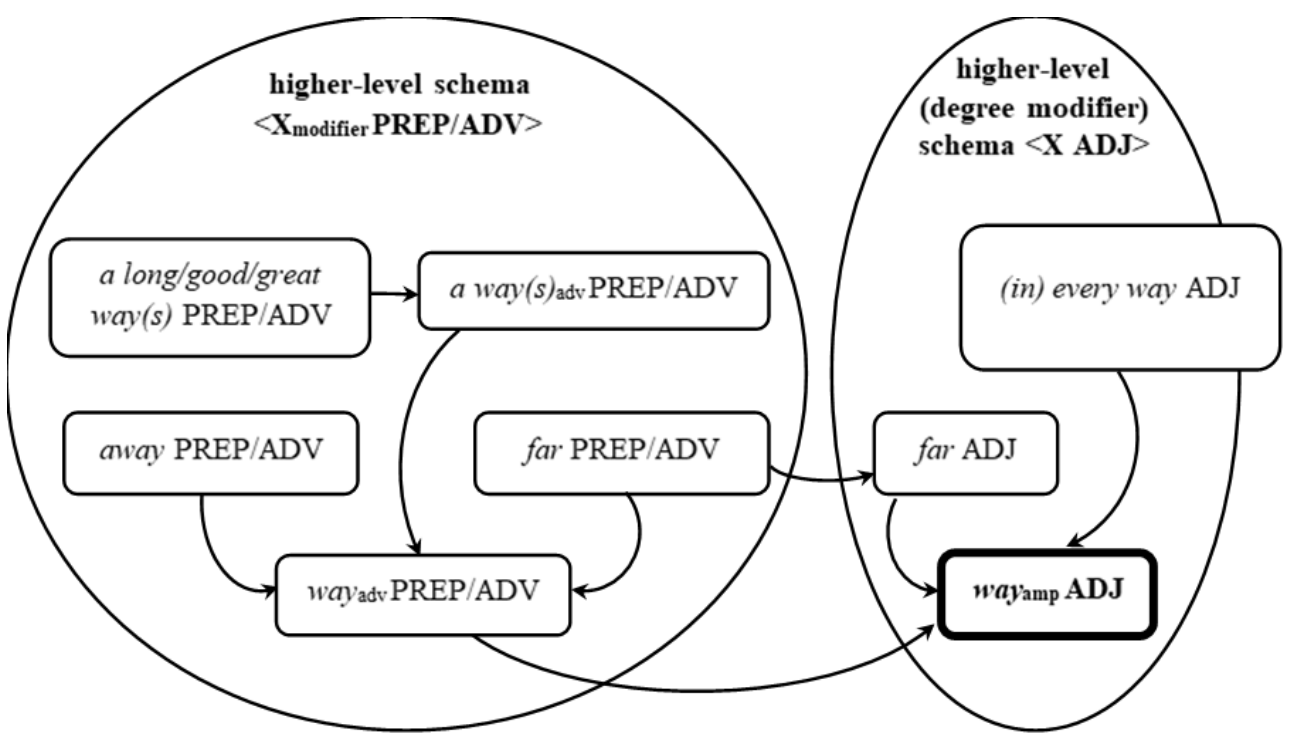

Figure 5 shows quite clearly how, by hypothesis, multiple source constructions interacted in the course of development of the amplifier way, both on a micro- and a macro-level. On the micro-level the construction $<w^{2} y_{\text {adv }}$ PREP/ADV $>$ appears to be a major source of development as it allows for exemplar-based ${ }^{22}$ analogization both from a syntactic and a semantic viewpoint. Indeed, way already takes on the function of modifier in this pattern and it has a general heightening effect. I propose that the development of the amplifier way-construction which the micro-schema $<_{\text {way }}$ adv $_{\text {PREP/ }}$ $A D V>$ was giving way to was further favoured by the amplifier-like function of the phrase (in) every way. Note that the micro-schema $<w_{a y} y_{\text {adv }}$ PREP/ADV $>$ itself may have taken its source both in (a)way-based constructions and the micro-schema <far PREP/ $A D V>$, all of which instantiate a higher-level shema, i.e. $\angle X$ PREP/ADV > whereby $X$ is any type of modifier. On the macro-level the change to amplifier way certainly involved some interaction with another higher-level schema, i.e. the degree modifier construction $\langle\mathrm{X} A \mathrm{ADJ}\rangle$, and micro-schemas that instantiate it such as $\langle$ far ADJ $>$.

This study thus departs from most traditional diachronic case studies which "[draw] straight lines between a construction and a historical ancestor", and suggests instead that the rise of the amplifier way can be envisaged as the outcome of "the blending of clearly distinct lineages" (Van de Velde et al. [2015: 1]). A corollary assumption is that several mechanisms or causes of change interacted, i.e. metaphorization, inferencing, 
and analogization, possibly mutually reinforcing each other. This is in line with the recent view that one can "come closer to a true understanding of the developments in question by considering multiple causes acting in concert or even independently" (Joseph [2015: 677]).

\section{BIBLIOGRAPHY}

AARON Jessi E., 2016, “The road already traveled: Constructional analogy in lexico-syntactic change", Studies in Language 40, 26-62.

ADAMSON Sylvia, 2000, "A lovely little example: Word order options and category shift in the premodifying string”, in FISCHER Olga, ROSENBACH Anette \& STEIN Dieter (Eds.), Pathways of Change: Grammaticalization in English, Amsterdam: John Benjamins, 39-66.

ALTENBERG Bengt, 1991, “Amplifier collocations in spoken English”, in JOHANSSON Stig \& STENSTRÖM Anna-Brita (Eds.), English Computer Corpora: Selected Papers and Research Guide, Berlin: Mouton de Gruyter, 127-147.

ANTILLA R., 2003, “Analogy: The warp and woof of cognition”, in JOSEPH Brian D. \& JANDA Richard D. (Eds.), The Handbook of Historical Linguistics, Oxford: Blackwell, 425-440.

BÄCKLUND Ulf, 1973, The Collocation of Adverbs of Degree in English, Uppsala: Acta Universitatis Upsalienlis.

BOLINGER Dwight, 1972, Degree Words, The Hague: Mouton de Gruyter.

BREBAN Tine \& DAVIDSE Kristin, 2016, "The history of very: The directionality of functional shift and (inter)subjectification", English Language and Linguistics 20(2), 221-249.

BREBAN Tine \& DE SMET Hendrik, 2019, "How do grammatical patterns emerge? The origins and development of the English proper noun construction", English Language and Linguistics 23(4), 879-899.

BUCHSTALLER Isabelle \& TRAUGOTT Elizabeth Closs, 2006, “The lady was al demonyak: Historical aspects of adverb all", English Language and Linguistics 10(2), 345-370.

CROFT William, 2001, Radical Construction Grammar: Syntactic Theory in Typological Perspective, Oxford: Oxford University Press.

CULPEPER Jonathan \& KYTÖ Merja, 2010, Early Modern English Dialogues: Spoken Interaction as Writing, Cambridge: Cambridge University Press.

DAVIES Mark, 2010- , The Corpus of Historical American English (COHA): 400 million words, 1810-2009, available online at https://www.english-corpora.org/coha/.

DAVIES Mark, 2012, "Some methodological issues related to corpus-based investigations of recent syntactic changes in English" in NEVALAINEN Terttu \& TRAUGOTT Elizabeth C. (Eds.), The Oxford Handbook of the History of English, Oxford: Oxford University Press, 263-287.

DE SMET Hendrik, 2013, Spreading Patterns: Diffusional Change in the English System of Complementation, Oxford: Oxford University Press. 
DE SMET Hendrik, 2016, "How gradual change progresses: The interaction between convention and innovation", Language Variation and Change 28, 83-102.

DE SMET Hendrik, D'HOEDT Frauke, FONTEYN Lauren \& VAN GOETHEM Kristel, 2018, “The changing functions of competing forms: Attraction and differentiation", Cognitive Linguistics 29(2), 197-234.

FETTIG Adolf, 1934, Die Gradadverbien im Mittelenglischen (Anglistische Forschungen 79), Heidelberg: Winter.

FILLMORE Charles J. \& KAY Paul, 1997, "Berkeley Construction Grammar", available at http:// www.isci.berkeley.edu/ kay/bcg/ConGram.html.

FISCHER Olga, 2007, Morphosyntactic Change: Functional and Formal Perspectives, Oxford: Oxford University Press.

FISCHER Olga, 2009, “Grammaticalization as analogically-driven change?”, Vienna English Working Papers 18(2), 3-23.

FISCHER Olga, 2013, "On the role played by analogy and the synchronic grammar system in processes of language change", Studies in Language 37(3), 515-533.

GOLDBERG Adele, 1995. Constructions: A Construction Grammar Approach to Argument Structure, Chicago: University of Chicago Press.

GOLDBERG Adele, 2006, Constructions at Work: The Nature of Generalization in Language, Oxford: Oxford University Press.

Green's Dictionary of Slang, available at https://greensdictofslang.com.

HEINE Bernd, 2002, "On the role of context in grammaticalization", in WISCHER Ilse \& DIEWALD Gabriele (Eds.), New Reflections on Grammaticalization, Amsterdam: John Benjamins, 83-101.

HIMMELMANN Nikolaus P., 2004, "Lexicalization and grammaticization: Opposite or orthogonal?", in BISANG Walter, HIMMELMANN Nikolaus P. \& WIEMER Björn (Eds.), What Makes Grammaticalization: A Look from its Components and its Fringes, Berlin: Mouton de Gruyter: 21-42.

HOPPER Paul \& TRAUGOTT Elizabeth Closs, 2003 [1993], Grammaticalization, Cambridge: Cambridge University Press.

ITO Rika \& TAGLIAMONTE Sali, 2003, “Well weird, right dodgy, very strange, really cool: Layering and recycling in English intensifiers", Language in Society 32(2), 257-279.

JUCKER Andréas H., 2018, “Apologies in the history of English: Evidence from the Corpus of Historical American English (COHA)”, Corpus Pragmatics 2(4), 375-398.

JUCKER Andréas H., FRITZ Gerd \& LEBSANFT Franz (Eds.), 1999, Historical Dialogue Analysis, Amsterdam: John Benjamins.

KIRCHNER Gustav, 1955, Gradadverbien: Restriktiva und Verwandtes im Heutigen English (Britisch und Amerikanisch), Halle, Germany: Max Niemeyer Verlag.

LABOV William, 1966, "Some principles of linguistic methodology", Language in Society 1, 97-120.

LABOV William, 1994, Principles of Linguistic Change: Internal Factors, Oxford: Blackwell.

LORENZ Gunter, 2002, "Really worthwhile or not really significant? A corpus-based approach to the delexicalisation and grammaticalization of intensifiers in Modern English", in WISCHER Ilse \& DIEWALD Gabriele (Eds.), New Reflections on Grammaticalization, Amsterdam: John Benjamins, 143161. 
MACAULEY Ronald, 2006, "Pure grammaticalization: The development of a teenage intensifier", Language Variation and Change 18, 267-283.

MÉNDEZ-NAYA Belén, 2003, “On intensifiers and grammaticalisation: The case of swīPE”, English Studies 84(4), 372-391.

MÉNDEZ-NAYA Belén, 2012, “A preliminary study of the history of the intensifier utterly", in MARTíN ALEGRE Sara, MOYER Melissa, PLADEVAll Elisabet \& TUBAu Susagna (Eds.), At a Time of Crisis: English and American Studies in Spain. Works from the $35^{\text {th }}$ AEDEAN Conference, Barcelona: Universitat Autònoma de Barcelona, 368-375.

NAPOLI Dona J. \& HOEKSEMA Jack, 2009, “The grammatical versatility of taboo terms”, Studies in Language 33, 612-643.

NEVALAINEN Terttu \& RISSANEN Matti, 2002, "Fairly pretty or pretty fair? On the development and grammaticalization of English downtoners", Language Sciences 24, 359-380.

NOËL Dirk, 2007, "Diachronic construction grammar and grammaticalization theory", Functions of Language 14(2), 177-202.

Oxford English Dictionary, available at http://www.oed.com.

PARADIS Carita, 1997, Degree Modifiers of Adjectives in Spoken British English, Lund: Lund University Press.

PARADIS Carita, 2000, “It's well weird: Degree modifiers of adjectives revisited: The nineties", in KIRK John M. (Ed.), Corpora Galore: Analyses and Techniques in Describing English, Amsterdam: Rodopi, 146-160.

PARADIS Carita, 2001, “Adjectives and boundedness”, Cognitive Linguistics 12, 47-65.

PETERS Hans, 1992, "English boosters: Some synchronic and diachronic aspects", in KELLERMANN Günter Alan \& MORISSEY Michaël D. (Eds.), Diachrony within Synchrony: Language History and Cognition, Frankfort: Peter Lang, 529-545.

PETERS Hans, 1994. “Degree adverbs in Early Modern English”, in KASTOVSKY Dieter (Ed.), Studies in Early Modern English, Berlin: Mouton de Gruyter, 269-288.

QUIRK Randolph, GREENBAUM Sidney, LEECH Geoffrey \& SVARTVIK Jan, 1985, A Comprehensive Grammar of the English Language, London: Longman.

STENSTRÖM Anna-Brita, 2000, “It's enough funny, man: Intensifiers in teenage talk”, in KIRK John M. (Ed.), Corpora Galore: Analyses and Techniques in Describing English, Amsterdam: Rodopi, 177-190.

STOFFEL Cornelis, 1901, Intensives and Downtoners: A Study in English Adverbs, Heidelberg: Carl Winter's Universitätsbuchhandlung.

TAGLIAMONTE Sali, 2008, "So different and pretty cool! Recycling intensifiers in Toronto Canada", English Language and Linguistics 12(2): 361-394.

TAGLIAMONTE Sali \& ROBERTS Chris, 2005, "So weird, so cool, so innovative: The use of intensifiers in the television series Friends", American Speech 80(3), 280-300.

TRAUGOTT Elizabeth Closs, 1995, “Subjectification in grammaticalization”, in STEIN Dieter \& WRIGHT Susan (Eds.), Subjectivity and Subjectivisation, Cambridge: Cambridge University Press, 31-54.

TRAUGOTT Elizabeth Closs, 2007, "The concepts of constructional mismatch and type-shifting from the perspective of grammaticalization", Cognitive Linguistics 18(4), 523-557. 
TRAUGOTT Elizabeth Closs, 2008a, "Grammaticalization, constructions and the incremental development of language: Suggestions from the development of degree modifiers", in ECKARDT Regine \& VEENSTRA Tonjes (Eds.), Variation, Selection, Development: Probing the Evolutionary Model, Berlin: Mouton de Gruyter, 219-250.

TRAUGOTT Elizabeth Closs, 2008b, “The grammaticalization of NP of NP constructions”, in BERGS Alexander \& DIEWALD Gabriele (Eds.), Constructions and Language Change, Berlin: Mouton de Gruyter, 21-43.

TRAUGOTT Elizabeth Closs, 2011 "Grammaticalization and mechanisms of change", in NARROG Heiko \& HEINE Bernd (Eds.), The Oxford Handbook of Grammaticalization, Oxford: Oxford University Press, 19-30.

TRAUGOTT Elizabeth Closs, 2015, “Towards a coherent account of grammatical constructionalization”, in BARðDAL Jóhanna, SMIRNOVA Elena, SOMMERER Lotte \& GILDEA Spike (Eds.), Diachronic Construction Grammar, Amsterdam: John Benjamins.

TRAUGOTT Elizabeth Closs, 2018a, "Modeling language change with constructional networks", in PONS BORDERÍA Salvador \& LOUREDA Óscar, Beyond Grammaticalization and Discourse Markers, Leiden: Brill, 17-50.

TRAUGOTT Elizabeth Closs, 2018b, "Rethinking the role of invited inferencing in change from the perspective of interactional texts", Open Linguistics 4(1), 19-34.

TRAUGOTT Elizabeth Closs, 2019, “Constructional pattern-development in language change”, in BUSSE Beatrix \& MOEHLIG-FALKE Ruth (Eds.), Patterns in Language and Linguistics, Berlin: Mouton de Gruyter, 125-156.

TRAUGOTT Elizabeth Closs \& DASHER Richard, 2002, Regularity in Semantic Change, Cambridge: Cambridge University Press.

TRAUGOTT Elizabeth Closs \& TROUSDALE Graeme, 2010, “Gradience, gradualness and grammaticalization: How do they intersect?", in TRAUGOTT Elizabeth Closs \& TROUSDALE Graeme (Eds.), Gradience, Gradualness and Grammaticalization, Amsterdam: John Benjamins, 19-44.

TRAUGOTT Elizabeth Closs \& TROUSDALE Graeme, 2013, Constructionalization and Constructional Changes, Oxford: Oxford University Press.

TROUSDALE Graeme, 2008, “Constructions in grammaticalization and lexicalization: Evidence from the history of a composite predicate construction in English", in TROUSDALE Graeme \& GISBORNE Nikolas (Eds.), Constructional Approaches to English Grammar, Berlin: Mouton de Gruyter, 33-70.

TROUSDALE Graeme, 2010, "Issues in constructional approaches to grammaticalization in English, in STATHI Katerina, GEHWEILER Elke \& KÖNIG Ekkehard, Grammaticalization: Current Views and Issues, Amsterdam: John Benjamins, 51-71.

TROUSDALE Graeme, 2012, “Grammaticalization, constructions and the grammaticalization of constructions", in DAVIDSE Kristin, BREBAN Tine, BREMS Lieselotte \& MORTELMANS Tanja (Eds.), Grammaticalization and Language Change, Amsterdam: John Benjamins, 167-198.

VAN DE VELDE Freek, DE SMET Hendrik, and GHESQUIÈRE Lobke, 2015, “Introduction: On multiple source constructions in language change", in DE SMET Hendrik, GHESQUIÈRE Lobke \& VAN DE VELDE Freek (Eds.), On Multiple Source Constructions in Language Change, Amsterdam: John Benjamins, 1-17. [First published in Studies in Language 37(3), 473-489] 
XIAO Richard \& TAO Hongyin, 2007, “A corpus-based sociolinguistic study of amplifiers in British English”, Sociolinguistic Studies 1(2), 241-273.

\section{NOTES}

1. I want to thank the two anonymous reviewers for their very thoughful and helpful comments. Any remaining errors are of course mine.

2. Used in a broad way, the term 'intensifier' includes "any device that scales a quality, whether up or down or somewhere between the two" (Bolinger [1972:17]).

3. Or 'wicked cool', as suggested by one reviewer.

4. In future research the study of the amplifier meaning of way could be extended to verbal and (non spatial) adverbial collocates.

5. For example, the Ditransitive Schema has several subschemas, including the Cause-not-receive subschema, which is realized with micro-schemas such as deny someone something.

6. The way-construction referred to in this paper differs from the way-construction illustrated in she giggled her way up the stairs.

7. Labov [1994: 11] notes that "historical documents survive by chance, not by design" and that they "are riddled with the effects of hypercorrection, dialect mixture, and scribal error". See, however, Traugott [2018a: 25-26] who, after recalling the several well-known hurdles scholars are faced with when studying language change, concludes that historical data is mostly not "bad data" provided they are rich, as is often the case for most recent eras.

8. To the best of my knowledge, there is, however, no corpus of historical American English that covers spoken data as such.

9. Jucker [2018] observes that fictional representations of spoken language are not substitutes for everyday spoken interaction but "merely show how authors chose to represent spoken interactions in their works of fiction".

10. One reviewer suggested that I also consider the pattern <every which way ADJ>, but no tokens were retrieved from COHA.

11. The OED dates it back much later to 1965.

12. The earliest example provided in Green's Dictionary of Slang actually dates back to 1888 . It is not mentioned in the present section as it shows the construct way below with a metaphorical meaning that I address later in Section 2.2.1.

13. The variant constructions $<w a y_{a m p} \mathrm{ADJ}_{a b s}>,<w a y_{a m p} \mathrm{ADJ}_{c m p}>$ and $<w a y_{a m p}$ too $\mathrm{ADJ}>$ are subsumed under the general heading <way ADJ>.

14. Note, however, that some (few) figures in Table 1 are biased because the pattern $<w_{a y}$ adv $\mathrm{PREP} / \mathrm{ADV}_{\text {spatial }}>$ is sometimes used very frequently by an individual speaker/writer. For instance, among the 37 tokens retrieved of the specific pattern <way ${ }_{\text {adv }}$ off $>$ in the 1880s, 27 are attributed to one single speaker/writer.

15. As observed in Section 2.1., the very first example provided in Green's Dictionary of Slang of the use of way as an amplifier shows way collocating not with an adjective but an adverb: (i) Congressional Record 3 Oct. 9122/1: He is way below, he is only 50 in mathematics. Interestingly, the whole sequence <way below $>$ in this example takes on the same kind of metaphorical meaning as the patterns I examine hereafter.

16. I did not conduct a quantitative analysis of the patterns < (in) no way ADJ> and <ADJ (in) no way $>$ because they are not directly related to the notion of high degree.

17. As one reviewer observed, it may be interesting to draw a parallel between, on the one hand, the uses of no way(s) as a negative maximizer, and way which scales at the opposite end of the 
scale, and, on the other hand, the interjection way used as a humorous response to no way: (i) 1992. D. Coupland Shampoo Planet X. 52 "You've become the cult Halloween costume for this year." "No way." "Way". (OED s.v. way int.2)

18. One reviewer observed that far also occurs in the superlative pattern. This is not the case, however, of the amplifier way, at least according to the data retrieved from COHA.

19. The fact that the schemas $<w_{a y}{ }_{\mathrm{amp}} \mathrm{ADJ}_{\mathrm{cmp}}>$ and $<w a y_{\mathrm{amp}}$ too $\mathrm{ADJ}>$ may have been attracted to and come to be aligned with the functionally similar schemas $<$ far $r_{\mathrm{amp}}$ $\mathrm{ADJ}_{\mathrm{cmp}}>$ and <far ${ }_{\mathrm{amp}}$ too ADJ> (see De Smet et al. [2018] for further detail on the concept of attraction) might explain why they are not considered to be slang, by contrast with the schema $<w_{a y} y_{\mathrm{amp}} \mathrm{ADJ} \mathrm{abs}_{\mathrm{s}}>$. By hypothesis, the preexisting schemas $<f a r_{\mathrm{amp}} \mathrm{ADJ}_{\mathrm{cmp}}>$ and $<$ far $_{\mathrm{amp}}$ too ADJ> favoured language users' acceptance of the innovative <way ${ }_{\mathrm{amp}} \mathrm{ADJ}_{\mathrm{cmp}}>$ and $<w_{a y}$ amp too ADJ> and the further conventionalization of these schemas.

20. The constructs <far different $>$, <far preferable>, <far inferior>, <far superior $>$ are not unrelated to $<f a r_{\mathrm{amp}} \mathrm{ADJ}_{\mathrm{cmp}}>$. With <far older>, for instance, there is a comparison between two (or more) entities on the basis of the property /old/. With <far different>, $<$ far preferable>, <far inferior $>$, or <far superior $>$, it is the adjectival head which captures the implicit notion of comparison. One needs to compare entity A to entity B before concluding that A is different from B. Similarly, if a speaker says that A is superior (to B), this means that A was previously compared to a reference point (B).

21. Note that because the particles collocating with a way(s) mainly have a spatial meaning and no metaphorical reading like a long way behind our race 'way inferior to our race' (see Section 2.2.1.), there is only one line representing the chronology of development of the pattern $<a$ way(s) PREP/ADV > while the development of $<$ way $_{\text {adv }}$ PREP/ADV $>$ and $<a$ long/good/great way $\mathrm{PREP} / \mathrm{ADV}>$ is represented along two paths, one for the literal spatial meaning of PREP/ADV, and one for a metaphorical reading hypothetically enabling the host-class expansion of the modifiers to adjectives (see Section 2.2.1.).

22. An exemplar is "an entrenched item stored in memory, typically a construction, to which another with partially similar properties is compared. If similar comparisons are made often enough by enough people, a pattern may be perceived that then becomes a model to which another item may be matched" (Traugott [2015: 64]).

\section{ABSTRACTS}

This article explores the diachronic semantic development of the intensifier way in American English. It has been claimed in the literature that the intensifying function of way derives from the use of spatial adverbial (a)way, but I propose that this may not be the only semantic source involved. This assumption is based on an examination of corpus data extracted from the Corpus of Historical American English. By suggesting that the high degree meaning of way originates from several source constructions, this article contrasts with most case studies on language change which generally focus on just one construction. It is also argued that several mechanisms or causes of semantic change may have played a part in the shift to intensifier function, i.e. metaphorization, pragmatic inferencing and analogization, motivated by semantically related constructions, most prominently the degree modifier construction <far ADJ>. A Diachronic 
Construction Grammar approach will highlight the importance of the architecture of grammar in the process of constructionalization which demands paying attention to constructions at various levels of schematicity to understand the semantic change under study here.

Cet article propose une étude diachronique du développement sémantique de l'intensifieur way en anglais américain. D'après la littérature, la fonction d'intensifieur de way dérive de l'emploi adverbial du marqueur spatial (a)way, mais l'hypothèse développée dans cet article est que ce n'est pas là son unique source de développement sémantique. Cette hypothèse se fonde sur une analyse de données extraites du Corpus of Historical American English. En suggérant que le sens de haut degré de way prend sa source dans plusieurs constructions, cet article se distingue de la plupart des études de cas sur le changement linguistique qui se concentrent généralement sur une seule construction. Une autre hypothèse avancée est que plusieurs mécanismes ou causes de changement sémantique ont joué un rôle dans le changement ayant conduit à l'emploi de way en tant qu'intensifieur, à savoir la métaphorisation, le processus d'inférence pragmatique et l'analogisation, motivée par des constructions sémantiquement proches, notamment la construction de degré <far $\mathrm{ADJ}>$. Une approche diachronique de la grammaire des constructions soulignera l'importance de l'architecture de la grammaire dans le processus de constructionalisation qui requiert que l'on s'intéresse à des constructions reflétant différents niveaux de schématicité pour comprendre le changement sémantique en jeu.

\section{INDEX}

Mots-clés: marqueurs de haut degré, sources de développement multiples, inférence pragmatique, développement analogique, métaphore, métaphorisation, constructionalisation Keywords: amplifiers, multiple source constructions, pragmatic inferencing, analogization, metaphor, metaphorization, constructionalization

\section{AUTHOR}

\section{HÉLÈNE MARGERIE}

Université Bordeaux Montaigne

helene.margerie@u-bordeaux-montaigne.fr 